\title{
$T$ cell receptor is required for differentiation but not maintenance of intestinal intraepithelial lymphocytes
}

\author{
Angelina M. Bilate ${ }^{1 *}$, Mariya London ${ }^{1 *}$, Tiago B. R. Castro ${ }^{1}$, Luka Mesin ${ }^{2}$, Suppawat \\ Kongthong ${ }^{1}$, Audrey Harnagel ${ }^{1}$, Gabriel D. Victora ${ }^{2}$, Daniel Mucida ${ }^{1}$ \\ ${ }^{1}$ Laboratory of Mucosal Immunology, The Rockefeller University, New York, NY 10065, \\ USA. \\ ${ }^{2}$ Laboratory of Lymphocyte Dynamics, The Rockefeller University, New York, NY 10065, \\ USA. \\ ${ }^{*}$ Contributed equally
}

Correspondence should be addressed to D.M. (mucida@rockefeller.edu)

P. $212-327-7520$

F. $212-327-8370$

RUNNING TITLE: Role of the TCR in IEL plasticity 


\section{Summary}

The gut epithelium is populated by intraepithelial lymphocytes (IELs), a heterogeneous $\mathrm{T}$ cell population with cytotoxic and regulatory properties. Migrating peripheral $\mathrm{CD} 4^{+} \mathrm{T}$ cells, including regulatory (Treg) and conventional T cells (Tconv), acquire an IEL (CD4IEL) program upon arrival at the epithelium. However, the specific role of the $T$ cell receptor $(T C R)$ in this process remains unclear. Single-cell TCR repertoire and transcriptomic analysis of intraepithelial $\mathrm{CD} 4^{+} \mathrm{T}$ cells revealed different extents of clonal expansion and TCR overlap between cell states; fully differentiated CD4-IELs from Tregs or Tconvs were the least diverse. Conditional deletion of TCR on differentiating $\mathrm{CD}^{+} \mathrm{T}$ cells or of MHCII on intestinal epithelial cells prevented CD4-IEL differentiation. However, TCR ablation on developed CD4-IELs did not affect their accumulation. These results indicate that local recognition of a limited set of antigens is an essential signal for the differentiation and adaptation of T cells to the epithelium. 


\section{Introduction}

T cell receptor (TCR) diversity of circulating T lymphocytes is ontogenically determined by thymic selection, but $\mathrm{T}$ cell localization and repertoire are largely dependent on exposure to, and recognition of, tissue-specific antigens (Hogquist and Jameson, 2014). In addition to these features, tissue imprinting influences $T$ cell subset differentiation and function (Faria et al., 2017). In the intestine, T cells located in the lamina propria (LP), and in the intraepithelial (IE) compartment display gut-specific characteristics, such as expression of gut-homing integrins, but differ markedly in TCR usage, migration patterns and function (McDonald et al., 2018).

Intestinal intraepithelial lymphocytes (IELs) comprise a heterogeneous population of $T$ cells, yet they all share common features such as tissue residency, cytotoxic potential, activated phenotype, and expression of CD8 $\alpha \alpha$ homodimers (Cheroutre et al., 2011; McDonald et al., 2018). Previous studies propose that CD8 $\alpha \alpha$ homodimers, in contrast to conventional CD8 $\alpha \beta$ heterodimers, work as TCR co-repressors by binding to thymus leukemia (TL) antigen expressed on epithelial cells, resulting in decreased antigen sensitivity of the TCR (Cheroutre and Lambolez, 2008). Similar to regulatory T cells (Treg) and invariant natural killer cells (iNKT), natural IELs (nIEL) such as CD8 $\alpha \alpha^{+}$TCR $\alpha \beta^{+}$are agonist-selected in the thymus (Leishman et al., 2002; Moran et al., 2011; Yamagata et al., 2004), suggesting an important role for TCR specificity in IEL development. Additionally, transgenic mice carrying an $\alpha \beta T C R$ from naturally-occurring CD8 $\alpha \alpha^{+} T C R \alpha \beta^{+} T$ cells preferentially differentiate towards this lineage, further 
indicating that TCR signaling strength itself may drive IEL fate (Mayans et al., 2014; McDonald et al., 2015; McDonald et al., 2014).

In addition to the developmentally-imprinted TCR features of intestinal T cells, luminal stimulation and other gut-enriched factors, such as microbial metabolites and epithelial cell factors, further influence peripheral T cell differentiation and plasticity (Atarashi et al., 2013; Lathrop et al., 2011; Sujino et al., 2016; Xu et al., 2018; Yang et al., 2014). Conventional CD4 ${ }^{+} \mathrm{T}$ cells and Tregs can differentiate into CD4-IELs expressing CD8 $\alpha \alpha$ in a microbiota-dependent manner upon migration to the gut epithelium (Bilate et al., 2016; Sujino et al., 2016). However, the role of TCR signaling in IEL differentiation, location and function has not been established. This is of particular interest given the relatively low abundance of MHC class II-expressing cells in the gut epithelium and other barrier surfaces (Faria et al., 2017).

We sought to address how TCR properties and signaling modulate the location and plasticity of $\mathrm{CD}^{+} \mathrm{T}$ cells in the intestine. We combined TCR repertoire analysis with single-cell transcriptomics using a fate-mapping strategy that allowed us to track Tregs and conventional T cells (Tconv) as they migrate to the intestinal epithelium and differentiate into CD8 $\alpha \alpha$-expressing IELs. Reduced TCR diversity was associated with terminal differentiation of CD4 ${ }^{+} \mathrm{T}$ cells into CD4-IELs; Tregs and intermediate stages were more diverse, whereas fully differentiated CD4-IELs were clonally restricted. Using in vivo genetic tools, we showed that ablation of surface TCR complexes on Tregs and other activated CD4 ${ }^{+}$T cells impaired CD4-IEL differentiation, suggesting that TCR 
expression is required for terminal T cell differentiation at the intestinal epithelium. Inducible deletion of MHC class II on intestinal epithelial cells (IEC) also prevented CD4-IEL differentiation, resulting in Treg accumulation at the epithelium. However, TCR ablation in fully differentiated CD4-IELs had little, if any, impact on their accumulation or on the maintenance of the IEL transcriptional program. Our findings indicate that TCR expression and local MHC class II on IECs are required for T cell plasticity at the intestinal epithelium, but not for the maintenance of the IEL program.

\section{Results}

\section{Clonal expansion of intraepithelial CD4 ${ }^{+} \mathrm{T}$ cells}

Specific TCR usage has been reported in both natural- and peripherally-induced Tregs located in distinct tissues, including the intestine (Fan and Rudensky, 2016; Lathrop et al., 2011; Liu et al., 2009; Zhou et al., 2009). While in most sites Tregs are thought to stably express Foxp3, we previously showed that a fraction of Tregs loses Foxp3 and acquires an IEL program, including CD8 $\alpha \alpha$ expression, upon migrating to the gut epithelium (Sujino et al., 2016). To define to what extent such plasticity is associated with specific TCR usage, we first analyzed the diversity of CD4 ${ }^{+} \mathrm{T}$ cells in the small intestine epithelium in wild-type (WT) mice using inducible Foxp3 fate-mapping coupled with Foxp3-reporter approaches. By crossing Foxp3 $3^{\text {eGFP-CreERT2 Rosa26 }} 6^{|s|-t d-T o m a t o}$ (iFoxp $3^{\text {Tom }}$ ) with Foxp $3^{\text {GFP }}$ mice (iFoxp $3^{\text {Tom }}$ Foxp $3^{\mathrm{GFP}}$ ), we were able to specifically analyze the TCR $\alpha \beta$ repertoire of four distinct subsets of IELs upon continuous tamoxifen administration: conventional $\mathrm{CD}^{+}{ }^{+} \mathrm{T}$ cells (CD8 $\alpha \alpha^{-}$, Tomato-, GFP-; Tconv), 
current Tregs (CD8 $\left.\alpha \alpha^{-}, \mathrm{GFP}^{+}\right)$and CD4-IELs originated from either Tconv (CD8 $\alpha \alpha^{+}$, Tomato $\left.{ }^{-}\right)$or from Tregs (CD8 $\alpha \alpha^{+}$, Tomato+; ex-Treg CD4-IEL) (Figure S1A). We compared the IEL TCR repertoire diversity with Tregs isolated from gut-draining mesenteric lymph nodes $(\mathrm{mLN})$ and lamina propria from the same animals by single-cell TCR $\alpha \beta$ sequencing (scTCRseq; Figure $1 \mathrm{~A}$ ). Cells with identical TCR $\beta$ CDR3 nucleotide sequences were considered as the same clones; additionally, clonality based on TCR $\beta$ CDR3s was confirmed by sequencing TCR $\alpha$ of the same expanded cells (Figure S1B).

We observed a diverse repertoire among Tregs isolated from $\mathrm{mLN}$; from 320 sequenced cells, we retrieved 313 unique clones (Figure 1A, B). TCR repertoire of Tregs and Tconv isolated from LP and IE was also diverse (Figure 1A, B). In contrast, we observed large clonal expansions and reduced TCR diversity among CD4-IELs and ex-Treg CD4-IELs (Figure 1A, B). Additionally, we detected clonal sharing between LP Tregs or Tconv and all IEL subsets analyzed: Tconv, CD4-IEL or ex-Treg CD4-IEL (Figure $1 \mathrm{~A}, \mathrm{C}$ ), suggesting that peripheral $\mathrm{CD} 4^{+} \mathrm{T}$ cells first migrate to the lamina propria before entering the epithelium or that the same $\mathrm{T}$ cell clones migrate simultaneously to both locations. Moreover, several expanded clones were shared between ex-Treg CD4-IELs (Tomato ${ }^{+}$) and CD4-IELs (Tomato-), including some with Tconv, raising the possibility that a single Tconv precursor can differentiate into Tregs and then to CD4-IELs, in addition to directly converting to CD4-IELs (Figure $1 \mathrm{~A}, \mathrm{C}$ ). Analysis of an additional iFoxp3 ${ }^{\text {Tom }}$ mouse showed similar results (Figure S1C, D). Because of the low proliferation capacity of CD4-IELs (Mucida et al., 2013), these 
results indicate that potential precursors migrate to the epithelium and proliferate before they can fully differentiate into CD4-IELs.

\section{Clonal distribution follows the trajectory of CD4-IEL differentiation}

Our previous live imaging and fate-mapping studies suggest that emigrating $\mathrm{CD} 4^{+} \mathrm{T}$ cells quickly acquire an IEL program at the gut epithelium while losing hallmarks of peripheral CD4 ${ }^{+} \mathrm{T}$ cells or Tregs, including the expression of ThPOK and Foxp3, respectively (Reis et al., 2013; Sujino et al., 2016). To concomitantly address intestinal epithelium-induced $\mathrm{CD}^{+} \mathrm{T}$ cell plasticity and specific TCR features in this process, we performed 5' single-cell RNA sequencing (scRNAseq) coupled to TCRseq analysis using the Chromium Single Cell V(D)J platform (10X Genomics). This strategy also allowed analysis of intra-mouse TCR sharing between current Tregs and ex-Treg CD4IELs, which was not possible in our dual Foxp3 reporter-fate-mapping strategy used above given that Foxp3 is X-linked. We analyzed tamoxifen-treated iFoxp3 ${ }^{\text {Tom }}$ mice by sorting all Tomato ${ }^{+}$(library 1 ) or Tomato- (library 2) CD4 ${ }^{+} \mathrm{CD} 8 \beta^{-}$T cells, therefore examining the whole spectrum of heterogeneity of $\mathrm{CD}^{+} \mathrm{T}$ cells that gained access to the epithelium. We confirmed the presence of CD4-IELs and Tregs in sorted cells by expression of CD8 $\alpha$ and Foxp3, respectively (Figure S2A). From the two libraries, we obtained a total of 1,294 scRNAseq profiles (898 for Tomato+ library 1 and 396 for Tomato- library 2) with paired $\alpha \beta$ TCR sequences for 952 cells (651 for Tomato+ library 1 and 301 for Tomato- library 2). 
We identified 8 clusters ordered by cell number (0-7) visualized by UMAP (Figure 2A, Figure S2B, Table S1), comparable to what we identified in our parallel unpublished study describing the molecular mechanisms of the differentiation towards CD4-IELs (London et al., unpublished). The cluster of cycling cells (7) was excluded from most of the downstream analysis due to low number of cells and strong proliferation gene signature that segregated them from all the other clusters. We identified three Treg clusters $(3,5$ and 6$)$ composed primarily of Tomato ${ }^{+}$cells that express genes ascribed to Tregs (Figure S2C,F, Table S1). Of note, cluster 5 contains cells with a profile of resting Tregs of lymphoid origin (Tcf7, II7r and Ccr7), includes a small subset of Sellexpressing cells (Naïve*) and was classified as recent emigrant Treg (RE-Treg; Figure S2D, Table S1). In addition to bona-fide Treg genes (Foxp3, Ikzf2 Capg), cells within Treg cluster 3 also express a profile associated to non-lymphoid tissue Tregs (Tnfrsf4, 9, 18 and Tigit) (Miragaia et al., 2019). A small fraction of cells in cluster 3 (TCR $\left.{ }^{*}\right)$ expressed high levels of Nr4a and Egr family members, related to increased TCR stimulation and activation (Zemmour et al., 2018). Treg-like (cluster 1) was ascribed to cells expressing a Treg profile, yet to a lower extent than the Tregs of cluster 3, while also expressing some IEL genes (Cd7 and Gzmb) (Table S1, Figure S2E). Finally, we identified three non-Treg clusters, one of them composed mostly of Tomato ${ }^{+}$cells (cluster 0), indicating Treg origin, while the other two (clusters 2 and 4) contained a mix

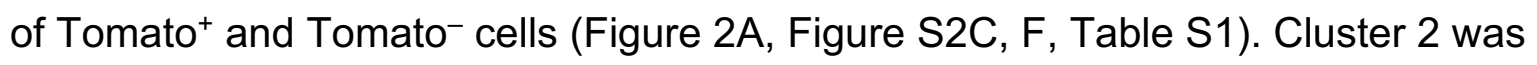
rather homogeneous containing CD8 $\alpha$-expressing cells with a "full IEL program" (Cheroutre et al., 2011; McDonald et al., 2018), which included the expression of Gzma, Gzmb, Cd244 (2B4), and Itgae (CD103) (Figure 2A, Figure S2C, Table S1). Trajectory 
analysis allowed the inference of a peripheral $\mathrm{CD} 4^{+} \mathrm{T}$ cell differentiation hierarchy as they gain access to the epithelium (Figure 2B). We observed three different potential trajectories, all leading to the differentiation of CD4-IELs from either Tregs (Tomato ${ }^{+}$) or from Tconv (Tomato ${ }^{-}$) (Figure 2B). Clusters 0 and 4 directly preceded the CD4-IEL cluster 2 and we refer to them as "pre-IEL1" (cluster 0) and "pre-IEL2" (cluster 4). Together, these findings suggest that CD4-IELs represent a final stage of differentiation, and that peripheral $\mathrm{CD}^{+} \mathrm{T}$ cells acquire a similar IEL program regardless of their origin (Tomato ${ }^{+}$or Tomato $^{-}$).

Overlaying the TCR $\alpha \beta$ repertoire information obtained from each cell on the UMAP clusters revealed variable levels of clonal expansion and spreading across the identified clusters (Figure 2C-F, Figure S2G,H). Consistent with our previous scTCRseq analysis, the CD4-IEL cluster was the least diverse cluster, as measured by the Chao1 index. Interestingly, although pre-IEL1 cluster 0 is not as diverse, it displayed similar level of clonal expansion, or dominance, as the CD4-IELs, as indicated by the low Diversity 50 (D50) score. Likewise, Treg and Treg-like clusters 3 and 1, respectively, displayed the next highest levels of clonal dominance (Figure 2E). Combination of pseudotime analysis (Figure 2B) with clonal distribution (Figure 2C, Figure S2G) and clonal diversity and dominance scores (Figure 2E), suggested that clonal expansion increased as cells developed towards CD4-IELs, but did not become homogeneous until the final CD4-IEL development stage. Furthermore, this analysis revealed a series of pathways through which different expanded clones differentiate from one state to another. This was especially true for fate-mapped cells, for which our tamoxifen labeling strategy served 
as a timestamp as Treg clones entered the epithelium, differentiated into pre-IELs and then into ex-Treg CD4-IELs. All of the top expanded clones that were present among the CD4-IELs were also found in at least one more cluster, with distributions that tended to follow the pseudotime trajectories (Figure 2C, D, F), suggesting expanded CD4 ${ }^{+} \mathrm{T}$ cells undergo differentiation at the epithelium. Our clonal composition analysis also indicates that terminal differentiation of CD4-IELs directly correlates with reduction in TCR diversity (Figure 2E). For example, the top expanded Treg-derived Tomato+ clones (clones 1TP and 7TP) were present in Treg, Treg-like, pre-IEL1 and CD4-IEL clusters, while some other expanded clones (clones 3TP, 4TP, 6TP, 9TP,10TP, 12TP) were not found among CD4-IELs but were shared between Tregs, Treg-like and pre-IEL1 clusters. Of note, the top expanded Tconv-derived Tomato- clones were found within pre-IEL2 and CD4-IEL clusters (Figure 2F, Table S2). It is possible that a fraction of T cell precursors did not receive sufficient signals to convert into CD4-IELs, or that the time required for conversion was longer than the timeframe of our analysis. Overall, our findings reveal a high degree of TCR sharing between rather heterogeneous gut $\mathrm{CD}^{+} \mathrm{T}$ cell populations, with reduced diversity as cells differentiate into IELs.

\section{Decreased TCR signaling precedes IEL differentiation}

Analysis of the scRNAseq data showed that acquisition of IEL markers, such as Itgae (CD103) by $\mathrm{CD}^{+} \mathrm{T}$ cells in the epithelium, is inversely correlated with expression of genes downstream of TCR signaling and co-stimulation, such as Nr4a1 (Nur77) and Tnfrsf4 (OX40). As pre-IELs acquire IEL and cytotoxic markers, they downmodulate TCR signaling molecules (Figure 3A, B). To confirm that downstream TCR signaling is 
associated with peripheral IEL differentiation, we analyzed Nur77 expression along differentiating peripheral IELs using Nur77 GFP Foxp3 $3^{\text {RFP }}$ reporter mice (Figure S3 A-C). CD4-IELs and $C D 4^{+}$CD $103^{+}$cells, which are enriched in pre-IELs, express lower levels of Nur77 when compared to recently-emigrated CD4 ${ }^{+} \mathrm{CD} 103^{-}$cells or to Tregs found in the epithelium (Figure 3C). Thus, Nur77 expression is inversely associated with acquisition of CD103 and CD8 $\alpha \alpha$ by $C D 4^{+} \mathrm{T}$ cells in the epithelium, suggestive of a role for TCR signaling in IEL differentiation from peripheral CD4+ ${ }^{+}$cells.

\section{TCR signaling is required for CD4-IEL development}

To directly assess the requirement of the TCR for CD4-IEL differentiation, we employed multiple Cre-mediated TCR ablation strategies targeting different stages or subsets of $\mathrm{CD}^{+} \mathrm{T}$ cells. First, we addressed whether TCR signaling is required for Treg plasticity in the gut epithelium and subsequent CD4-IEL differentiation by crossing Trac $^{\mathrm{f} / \mathrm{f}}$ mice to iFoxp3 $3^{\text {Tom }}$ mice (to generate the iFoxp $3^{\text {Tom } \Delta(T r a c)}$ strain), which allowed for the tracking of ex-Tregs as they lose surface TCR expression (Figure 4A,B, Figure S4A,B). Whereas CD4-IEL differentiation from TCR-expressing (TCR $\beta \mathrm{S}^{+}$; Tomato- or Tomato ${ }^{+}$) cells was similar between $\mathrm{i} F o x p 3^{\text {Tom }}$ and iFoxp $3^{\operatorname{Tom} \Delta(\operatorname{Trac})}$ mice, it was significantly impaired among TCR-deficient (TCR $\beta \mathrm{S}^{-}$Tomato $^{+}$) cells of iFoxp3 ${ }^{\text {Tom } \Delta(T r a c)}$ mice (Figure 4A, B, Figure S4C). Our scRNAseq data showed that Tnfrsf4 (OX40) expression changed in a developmentally controlled manner, peaking in Treg cluster 3 and then rapidly decaying by pre-IEL clusters 4 and 0 (Figure 3A, B). This pattern of expression allowed us to use the well-established OX40 ${ }^{\text {Cre }}$ driver (Reis et al., 2013) to delete the TCR from IEL precursors but not from IELs themselves. We confirmed TCR deletion in activated CD4 ${ }^{+}$ 
T cells and Tregs in the $\mathrm{mLN}$ of $\operatorname{Trac}^{\mathrm{f} / \mathrm{f}} \times \mathrm{OX} 40^{\mathrm{Cre}}\left(\mathrm{OX} 40^{\Delta(\operatorname{Trac})}\right)$ mice by flow cytometry (Figure S4F-J). In the epithelium, while the total frequency of CD4 ${ }^{+} \mathrm{T}$ cells remained the same in OX40 $\mathrm{WT}^{(\text {Trac })}$ and OX40 ${ }^{\Delta(\text { Trac) }}$ mice (Figure S4D), TCR ablation significantly decreased the CD4-IEL population (Figure 4C, D, Figure S4E). We further compared the frequencies of CD4-IELs among TCR-sufficient and TCR-deficient CD4 ${ }^{+} \mathrm{T}$ cells in OX40 ${ }^{\Delta(T r a c)}$ mice based on surface TCR $\beta$ expression. CD4-IELs were only observed among TCR-sufficient cells (Figure 4E). Taken together, our data indicate that the differentiation of both Treg and Tconv to CD4-IELs requires TCR expression.

\section{MHCII expression on epithelial cells modulates CD4-IEL differentiation}

Recent studies have suggested a role for intestinal epithelial cell (IEC)-mediated antigen presentation via $\mathrm{MHCll}$ in the regulation of intestinal $\mathrm{CD}^{+} \mathrm{T}$ cell function (Biton et al., 2018; Koyama et al., 2019). We therefore asked whether local MHCIl expression by IECs is required for CD4-IEL differentiation or maintenance. We targeted MHC class II expression exclusively on IECs by crossing Villin CreERT2 mice to $H 2-A b 1^{f / f}$ mice $\left(\right.$ Villin $^{\Delta(\mathrm{MHCII})}$ (Figure S5A-C). Tamoxifen treatment of Villin ${ }^{\Delta(\mathrm{MHCII})}$ mice starting at 5-7 weeks of age (prior to the appearance of CD4-IELs in the epithelium) did not affect the frequency of total $C D 4^{+} \mathrm{T}$ cells in the epithelium 5-6 weeks later; however, it led to a significant reduction in the frequency of CD4-IELs, which was accompanied by an increase in Treg frequency (Figure 5A). Tamoxifen treatment of 11, 12- or 16-week-old mice, which typically carry a sizable population of CD4-IELs, also significantly impacted CD4-IEL frequencies and conversely led to an accumulation of Tregs in the epithelium 
(Figure 5B, C), suggesting that MHCII expression on IECs is required for continuous differentiation into CD4-IELs in adult mice.

\section{TCR signaling is largely dispensable for IEL program maintenance}

The transition to an IEL program includes upregulation of NK- and cytolytic- molecules as well as CD8 $\alpha \alpha$ (Cheroutre et al., 2011; McDonald et al., 2018), with concomitant downregulation of TCR signaling. To evaluate the role of the TCR signaling in establishing the IEL program, and in the maintenance of differentiated IELs, we crossed $\operatorname{Trac}^{\mathrm{fff}}$ mice to those expressing Cre under the enhancer I of the Cd8a gene $\left(\mathrm{E}_{8}{ }^{\Delta(\operatorname{Trac})}\right)$. E8, is required for CD8 $\alpha$ expression on mature T cells and CD8 $\alpha \alpha$ IELs, but not required for $\mathrm{CD} 8 \alpha \beta$ or $\mathrm{CD} 8 \alpha \alpha$ expression in developing thymocytes (Ellmeier et al., 1997). In E8 ${ }^{\Delta(\text { Trac })}$ mice, TCR deletion is accompanied by a decrease in CD8 $\alpha-$ expressing TCR $\alpha \beta^{+}$cells in the $\mathrm{mLN}$ and IE, including CD4-CD $8 \beta^{+} \mathrm{CD} 8 \alpha^{+} \mathrm{T}$ cells and CD4-CD8 $\beta^{-} \mathrm{CD} 8 \alpha \alpha^{+}$TCR $\alpha \beta^{+}$natural IELs (nIEL) (Figure S6A-F). In the case of peripheral $\mathrm{CD} 4^{+} \mathrm{T}$ cells, which only express CD8 $\alpha \alpha$ in the final stages of their differentiation into CD4-IEL, this model allowed us to selectively address the role of the TCR in the maintenance of differentiated CD4-IELs. We did not observe any significant changes in the accumulation of CD4-IELs in E8, ${ }^{\Delta(T r a c)}$ mice when compared to WT littermates $\left(\left.E_{8}\right|^{W T(T r a c)}\right)$, even in older animals (Figure $\left.6 A, B\right)$, suggesting that upon terminal differentiation, CD4-IELs do not rely on the TCR for their maintenance in the epithelium. Whereas proliferation, measured by Edu incorporation, was similar among Tconv from E8, ${ }^{\mathrm{WT}(T r a c)}$ and $\mathrm{E}_{\mathrm{I}^{\Delta(T r a c)}}$ mice, remaining TCR-expressing CD4-IELs in $\mathrm{E}_{8}{ }^{\Delta(T r a c)}$ mice proliferated more than those of $\mathrm{E} 8 \mathrm{I}^{\mathrm{WT}(\mathrm{Trac})}$ mice, but only in older animals 
(Figure 6C, D). Therefore, similar frequencies of CD4-IELs cannot be exclusively attributed to differential proliferative abilities of TCR-sufficient and TCR-deficient cells. Similar proliferation rates were observed in other CD8 $\alpha \alpha$-expressing IEL subsets, including CD8 $\alpha \beta^{+} C D 8 \alpha \alpha^{+}$TCR $\alpha \beta^{+}$(CD8-IELs) and CD8 $\alpha \alpha^{+}$nIELs (Figure S6G, H). Common IEL functional readouts such as IFN $\gamma$ production and granzyme B expression showed that hallmarks of the CD4-IEL phenotype are maintained in the absence of the TCR (Figure 6E, F). Analysis of CD8-IELs and nIELs also revealed intact IFN $\gamma$ and granzyme B production, despite TCR loss (Figure S6I-L). Taken together, our results suggest that CD4-IEL accumulation and at least some of the characteristic features of IELs are maintained in the absence of TCR signaling.

To comprehensively address the extent to which the IEL program can be affected or maintained in the absence of TCR signaling, we performed bulk RNAseq on TCRexpressing CD4-IELs from E8, ${ }^{\mathrm{WT}(\mathrm{Trac})}$ mice and on TCR-deficient CD4-IELs from $E 8_{1}^{\Delta(T r a c)}$ mice (Figure S6M). While genes related to TCR activation or signaling, cell cycle or proliferation, anti-apoptosis and protein transport showed reduced expression in cells lacking their TCR, most IEL-related genes were not significantly changed in $E 8^{\Delta(T r a c)}$ mice, suggesting the IEL program is maintained in the absence of TCR expression (Figure 6G-I, Table S3). Gene ontology (GO) enrichment analysis showed that only a few pathways, such as protein phosphorylation, were upregulated in TCRdeficient cells (Figure 6H). Likewise, IEL genes were not changed among CD8-IELs or nIELs in $E 8_{1}^{\Delta(T r a c)}$ mice, but genes related to TCR signaling were significantly decreased in TCR-deficient cells (Figure S6 N,O, Table S4,5). Of note, Lag3 (Lymphocyte 
activation gene-3), a TCR inhibitory co-receptor, was downmodulated in all 3 IEL subsets lacking TCR expression (Figure 6G, Table S1).

To further evaluate whether the TCR confers any competitive advantage to IELs, we reconstituted sub-lethally irradiated $R a g 1^{-/-}$mice with a $1: 1$ mix of congenically-marked bone marrow from WT CD45.1 and E8, ${ }^{\Delta(\text { Trac })}$ CD45.2 mice (Figure 6J). Whereas the ratio of WT to $E 8_{1}^{\Delta(T r a c)}$ remained approximately $1: 1$ in non- $\alpha \beta T$ cells, this ratio was significantly skewed towards WT among CD8-IELs (Figure 6J,K), indicating that TCRdeficient CD8-IELs were outcompeted by TCR-expressing cells. In contrast, within both nIELs and CD4-IELs, the WT: E8, ${ }^{\Delta(T r a c)}$ ratio was much less skewed, and surface-TCR $\beta^{-}$ cells were readily detected among these populations (Figure 6J). Thus CD4-IELs are much less sensitive than CD8-IELs to TCR loss. Together, our data establish an important role of TCR in IEL differentiation, particularly in the final stages within the epithelium, but also indicate that TCR signaling is mostly dispensable for CD4-IEL maintenance.

\section{Discussion}

Self-reactive T cell populations with regulatory properties such as natural Tregs, iNKT cells, and CD8 $\alpha \alpha$ IELs are selected via agonist-selection, a process that favors development of cells with strong TCR avidity despite of self-reactivity (Sakaguchi et al., 2013; Yamagata et al., 2004). However, much less is known about how TCR signaling and repertoire impact tissue-induced plasticity and the differentiation of peripheral $\mathrm{T}$ cells which are presumably selected on weaker but broader TCR affinity interactions. 
Our study revealed a previously unappreciated degree of TCR sharing between largely distinct $\mathrm{CD}^{+} \mathrm{T}$ cell subsets in the periphery, distinct levels of clonal expansion and TCR diversity along differentiating IELs, and a specific requirement for TCR signaling during the early stages of the IEL differentiation process.

Early analyses of TCR diversity in nIEL subsets revealed a restriction in TCR repertoire, referred to as "oligoclonal repertoire" (Guy-Grand et al., 1991; Regnault et al., 1994; Regnault et al., 1996; Rocha et al., 1991). More recently, work using a TCR ${ }^{\text {mini }}$ mouse model harboring restricted TCR $\alpha$ and TCR $\beta$ repertoires showed a substantial TCR overlap between CD4-IELs and Tregs (Wojciech et al., 2018). In addition to the agonist selection of thymic IEL precursors (Leishman et al., 2002; Yamagata et al., 2004), studies that generated transgenic mouse strains carrying existing IEL $\alpha \beta T C R s$ strongly suggested that TCR specificity may be sufficient to drive IEL fate (Mayans et al., 2014; McDonald et al., 2014). It remained unclear, however, how specific TCRs correlate with IEL differentiation. Our scRNAseq and trajectory analyses coupled to TCR repertoire allowed us to unbiasedly define the relationship between TCR diversity and CD4 ${ }^{+}$T cell plasticity during migration and differentiation towards IELs. Expanded clones followed pseudotime trajectory analysis and displayed intra-clonal plasticity: less expanded clones spread among heterogenous subsets, while highly expanded clones were found in the homogenous cluster of CD4-IELs. A possible explanation for this finding is that the less expanded clones lacked additional signals, such as TCR ligands or environmental components, required for full differentiation into CD4-IELs (CervantesBarragan et al., 2017; Cortez et al., 2014; Mucida et al., 2013; Reis et al., 2014; Reis et 
al., 2013). The clonal analyses presented here, including the TCR sharing of CD4-IELs derived from Treg or from Tconv, corroborate previous studies suggesting a lineage relationship between Tregs and IELs (Bilate et al., 2016; Sujino et al., 2016).

Additionally, their clonal distribution suggest that IEL differentiation may favor particular TCR specificities, perhaps in a process analogous to peripheral Treg differentiation, where TCR recognition in a context-dependent manner leads to Foxp3 expression (Curotto de Lafaille et al., 2004; Mucida et al., 2005).

Despite of being "chronically activated" as defined by the expression of activation markers such as CD69 and CD44 (Mucida et al., 2013), CD4-IELs do not show signs of strong TCR activation. We find that Nur77, which is expressed proportionally to the strength of the TCR stimulation, is increased in migrating CD4 ${ }^{+} \mathrm{T}$ cells but is progressively down-modulated as they differentiate into pre-IELs. This is similar to the high level of Nur77 displayed by agonist-selected T cells such as iNKT cells during thymic selection, which subsequently decays upon migration of these cells to the spleen or liver (Moran et al., 2011). While the majority of CD4-IELs express low levels of Nur77, a small fraction of them maintained Nur77 expression, suggesting that TCR reengagement can be modulated within the epithelium. Indeed, availability of antigens presented by IEC could function in the late-stage of IEL differentiation, possibility supported by the decreased CD4-IEL population upon MHCII targeting on IECs. The modulation of MHCII expression by IECs has been linked to the capacity of microbes to attach to the epithelium, and to IFN $\gamma$ production in both human and murine models (Ivanov et al., 2009; Panja et al., 1998; Umesaki et al., 1995). MHCII expression by 
IECs has been recently associated with a variety of physiological, such as regulation of the stem cell niche, and pathological functions, such as CD4 ${ }^{+} \mathrm{T}$ cell-mediated inflammation during graft-versus-host disease, in part through interacting with gut resident T cells that provide cytokines (Biton et al., 2018; Koyama et al., 2019; Ladinsky et al., 2019). Our data suggests a model in which antigen presentation by IECs is instrumental for the differentiation of CD4-IELs, which may further enhance MHCII expression by IECs via IFN $\gamma$ production. Whether this is exclusively dependent on antigen presentation by IECs needs further demonstration. Regardless, the TCR complex itself, and presumably antigenic stimulation, is important for CD4-IEL differentiation as demonstrated by TCR ablation on OX40-expressing cells as well as on Tregs, which then precluded the differentiation into CD4-IELs.

However, our results show that TCR ablation on CD4-IELs does not impair their persistence in the epithelium nor the production of IFN $\gamma$ and granzyme B. This is consistent with the decreased antigen sensitivity and increased threshold for TCR activation in cells expressing CD8 $\alpha \alpha$ homodimers (Cheroutre and Lambolez, 2008). Furthermore, our RNAseq analysis suggests that despite the down-modulation of genes downstream of TCR activation in TCR-deficient CD4-IELs, the maintenance of an IEL program may not depend on continuous TCR signaling. This is in contrast to the requirement of TCR expression on mature Tregs for their suppressive function and maintenance of an effector Treg program (Levine et al., 2014). The extent to which CD4-IELs depend on TCR signaling for specific functions and whether it is needed in 
discrete modules during different stages of differentiation from Tregs to CD4-IELs remains to determined.

Although surface expression of T cell receptors did not significantly impact CD4-IEL maintenance, TCR signaling and local MHC class II expression on IECs are essential for T cell plasticity at the epithelium. Given the potential abundance of antigens to which the intestinal epithelium is exposed, the restricted TCR diversity of CD4-IELs is intriguing. It is likely that CD4-IELs recognize a restrict set of peptide-MHCII complexes. The origins (microbial or dietary), and the range of TCR specificities and affinities for these antigens recognized by CD4-IELs still remains to be elucidated. This will help address the impact of $\mathrm{MHC}$ class II-restricted immune responses at the intestinal epithelium. 


\section{Acknowledgements}

We are grateful to A. Rogoz, J. Bortolatto and S. Gonzalez for exceptional animal care, mouse colony management and genotyping and the Rockefeller University employees for continuous assistance. We thank K. Gordon and K. Chhosphel for assistance with cell sorting. We thank C. Zhao and the entire Genomics Core of Rockefeller University for library preparation for $10 \mathrm{X}$ Genomics and assistance with all sequencing platforms used in this paper. We thank the NIH tetramer core facility for providing the TL tetramers used in this study. We are grateful to J. Lafaille for support throughout this project. We thank B. Reis for suggestions and critical reading of the manuscript, and all the members of the Mucida lab for fruitful discussions.

\section{Funding}

This work was supported by NIH grant PHS DK093674 and R01DK113375. DM is also supported by Burroughs Wellcome Fund, Black Family Metastasis Center and the Kavli Foundation.

\section{Author contribution}

$\mathrm{AMB}, \mathrm{ML}$ and $\mathrm{DM}$ conceived the study, designed experiments and wrote the manuscript. AMB and ML performed and analyzed experiments. TBRC performed all bioinformatics analyses and assisted with interpretation of sequencing data. $\mathrm{AH}$ and SK helped with single-cell PCRs and multiplexing of samples for scTCRseq. LM helped with analysis of scTCRseq by Miseq, library preparation of bulk RNAseq and with calculation of diversity index, under the supervision of GDV. 
bioRxiv preprint doi: https://doi.org/10.1101/2020.06.04.134510; this version posted June 5, 2020. The copyright holder for this preprint (which was not certified by peer review) is the author/funder. All rights reserved. No reuse allowed without permission.

\section{Declaration of interest}

The authors declare no conflict of interest. 


\section{Figure Legends}

Figure 1. CD4-IELs are clonally expanded with decreased TCR diversity. (A-C) Foxp $3^{\text {eGFP-Cre-ERT2 }} \times$ Rosa26 $^{\text {Isl-tdTomato }} \times$ Foxp3 $^{\text {IRES-GFP }}$ (iFoxp3 $3^{\text {Tom }}$ Foxp ${ }^{\text {GFP }}$ ) mice were treated with tamoxifen for 10 weeks, and $\mathrm{CD} 4^{+} \mathrm{T}$ cells from mesenteric lymph nodes (mLN), lamina propria (LP) and intestinal epithelium (IE) were sorted as follows: $\mathrm{CD}^{+}$conventional (Tconv; GFP-Tomato-CD8 $\left.\alpha^{-}\right)$, regulatory T cells (Treg; GFP ${ }^{+}$or Tomato $\left.{ }^{+} \mathrm{CD} 8 \alpha^{-}\right)$, ex-Treg CD4-IEL (Tomato+CD8 $\left.\alpha^{+}\right)$and CD4-IEL (GFP-TomatoCD8 $\left.\alpha^{+}\right)$. TCR $\beta$ were sequenced via the MiSeq platform. TCR $\alpha$ of expanded TCR $\beta$ clones were also sequenced to confirm clonality. (A) TCR $\beta$ clonal diversity of indicated populations from two separate mice. Each slice represents a distinct TCR $\beta$ CDR3. Colored clones represent sharing within each mouse. White slices represent unique clones and grey-scale slices represent expanded clones at indicated populations. The numbers enclosed in each graph indicates number of clones (numerator) and total number of cells (denominator) per indicated population. Empty graphs with "ND" indicate no data for corresponding cell types. (B) Diversity estimated by Chao1 estimate (left) and D50 (right) of indicated cells in two separate mice based on their TCR $\beta$ CDR3s. (C) Normalized Morisita index (top right) and number of shared clones (bottom left) of TCR $\beta$ CDR3s per cell type of both mice.

Figure 2. Clonal distribution of intraepithelial $\mathrm{CD4} 4^{+} \mathrm{T}$ cells follows the single-cell trajectories. 


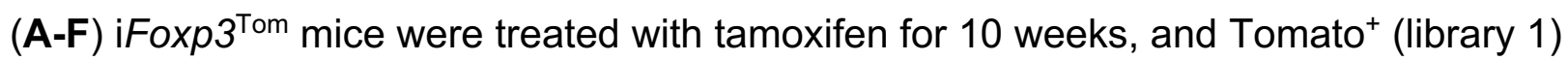
and Tomato- (library 2) $\mathrm{CD}^{+}{ }^{+} \mathrm{T}$ cells from the intestinal epithelium (IE) were sorted for scRNAseq using 10X Genomics platform. (A) UMAP clustering of 8 (0-7) distinct populations of single cells, including sub-clusters (3a, 5a). Sub-cluster 3a_Treg $\left(T_{C R}^{*}\right)$ indicates Tregs expressing TCR-stimulated genes. Sub-clusters 5a_RE-Treg (Naïve*) indicates Sell-expressing Tregs. Cluster names correspond to cell colors throughout the figure as indicated. (B) Pseudotime trajectory analysis of Tomato ${ }^{+}$(top left) and Tomato ${ }^{-}$ (top right) cells. Cells on UMAP clusters ordered along diffusion component 1 (DC1), colored according to cluster (bottom left) or tomato expression (bottom right). (C) Paired $\alpha \beta T C R$ CDR3 of cells per UMAP cluster ordered by pseudotime trajectories of Tomato ${ }^{+}$ (TP, shades of red) and Tomato- (TN, shades of blue) cells. Lightest shades indicate unique clones, intermediate shades indicate expanded, but not shared clones within TP or TN. Darkest shades of red or blue indicates $\alpha \beta T C R$ sharing between clusters per TP or TN, respectively. (D) Normalized Morisita index (top right) and absolute number of shared clones (Clone overlap, bottom left) of paired $\alpha \beta T C R$ per UMAP cluster among tomato positive cells. (E) Diversity estimated by Chao1 estimate (left) and D50 (right) of cells based on paired $\alpha \beta T C R$ per indicated cluster. $(\mathbf{F})$ Top expanded clones per tomato positive (TP, red and blue) and negative (TN, orange and green) indicated in UMAP clusters, separated by tomato expression. Dashed line indicates top limit of CD4-IEL cluster 2.

Figure 3. Intraepithelial $\mathrm{CD}^{+} \mathrm{T}$ cell subsets show an inverse correlation between TCR signaling and IEL program. 
(A, B) iFoxp $3^{\text {Tom }}$ mice were treated with tamoxifen for 10 weeks, and Tomato+ (library 1) and Tomato- (library 2) $\mathrm{CD}^{+}{ }^{+} \mathrm{T}$ cells from the intestinal epithelium (IE) were sorted for scRNAseq using 10X Genomics platform. (A) Expression levels of genes related to TCR signaling or IEL program in each UMAP cluster ordered by pseudotime trajectories. (B) Expression levels of Egr and Nr4a families (left), Tnfrsf4 (OX40, middle) and Itgae (CD103, right) in all sequenced cells. (C) Nur77 as measured by GFP fluorescence expression levels (left) and frequencies (right) among Foxp ${ }^{+}$regulatory $\mathrm{T}$ cells $\left(\mathrm{RFP}^{+}\right.$, Treg, blue), conventional CD4 ${ }^{+} \mathrm{T}$ cells (RFP'-, CD8 $\alpha^{-}$, Tconv) $\mathrm{CD} 103^{-}$ (grey) or $\mathrm{CD}^{103^{+}}$(black) cells, and CD4-IELs (RFP-, CD8 $\alpha^{+} \mathrm{TL}^{-}$Tetramer ${ }^{+}$, red) in the small intestinal epithelium of SPF Nur77 ${ }^{\text {GFP Foxp }} 3^{\text {RFP }}$ double-reporter mice.

\section{Figure 4. TCR signaling is required for CD4-IEL differentiation.}

(A, B) Flow cytometry analysis of the intestinal epithelium (IE) of iFoxp3 ${ }^{\text {TomWT(Trac) }}$

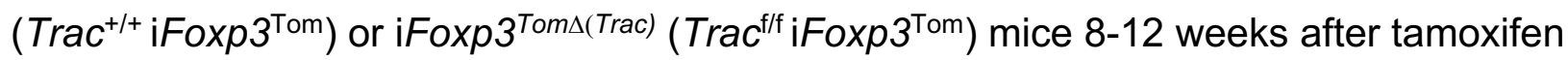
administration. (A) Representative dot plots of surface CD $8 \alpha$ and TCR $\beta$ of Tomato ${ }^{+}$ $\mathrm{CD}^{+}{ }^{+}$T cells in iFoxp $3^{\text {TomWT(Trac) }}$ (left) and iFoxp3 ${ }^{\text {Tom } \Delta(\text { Trac) }}$ (right) animals. (B) Frequencies of $\mathrm{CD} 8 \alpha^{+}$cells among Tomato ${ }^{+} \mathrm{CD} 4^{+} \mathrm{T}$ cells within TCR-sufficient cells from iFoxp3 ${ }^{\text {TomWT(Trac) }}$ (white bar) or iFoxp3 ${ }^{\text {Tom } \Delta(T r a c)}$ (grey bar) mice, or TCR-deficient cells from iFoxp3 ${ }^{\text {Tom }}{ }^{\text {(Trac) }}$ (red bar) mice. (C-E) Flow cytometry analysis of CD4 ${ }^{+} \mathrm{T}$ cells in the IE of 9-12-week-old OX40 WT(Trac) $\left(\right.$ Trac $^{+/+}$OX40Cre ${ }^{+/-}$or Trac $\left.^{f / f} \mathrm{OX} 40 \mathrm{Cre}^{-/-}\right)$or

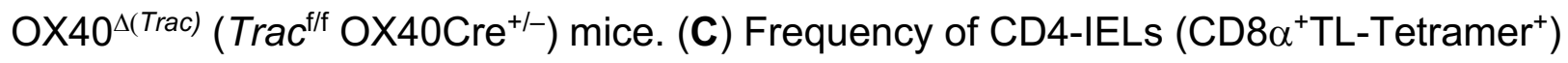
among CD4 ${ }^{+} \mathrm{T}$ cells. (D) Representative dot plots of surface CD8 $\alpha$ and TCR $\beta$ of $C D 4^{+} \mathrm{T}$ cells. (E) Frequencies of CD4-IELs among conventional CD4 ${ }^{+} \mathrm{T}$ cells (Tconv, 
$\mathrm{CD}^{+}{ }^{+} \mathrm{CD} 8 \alpha^{-} \mathrm{Foxp}^{-}$) within TCR-sufficient cells from OX40WT(Trac) (white bar) or $\mathrm{OX} 40^{\Delta(\text { Trac) }}$ (grey bar) mice, or TCR-deficient cells from $\mathrm{OX} 40^{\Delta(T r a c)}$ (red bar) mice. Data are expressed as mean $+/-$ SEM of individual mice $(n=5-16)$. Significant $p$ values as indicated [student's t test $(\mathbf{C})$ or one-way ANOVA and Bonferroni $(\mathbf{B}, \mathbf{E})]$.

Figure 5. MHCll expression by epithelial cells is required for CD4-IEL conversion. (A-C) Flow cytometry analysis of the intestinal epithelium (IE) of iVillin ${ }^{\text {WT(MHCII) }}$ (H2$A b 1^{+/+}$Villin CreERT2+/- or $H 2-A b 1^{\text {f/f }}$ Villin CreERT2-l- $^{\text {or iVillin }}{ }^{\Delta(M H C l l)}\left(H 2-A b 1^{\text {f/f }}\right.$ Villin $\left.^{\text {CreERT2+/+ }}\right)$ mice after tamoxifen administration to 5-7 week-old mice, analyzed at 10-12.5 weeks (A), to 10.5-12 week-old mice, analyzed at 13-17 weeks of age (B), to 16 week-old mice, analyzed at 21-22 weeks of age (C). Representative dot plots of surface CD8 $\alpha$ and TL- Tetramer among CD4 ${ }^{+} \mathrm{T}$ cells (left). Frequencies of CD4-IELs (CD4 ${ }^{+} \mathrm{CD} 8 \alpha^{+} \mathrm{TL}-$ Tetramer $^{+}$) or Foxp3 ${ }^{+}$regulatory cells (Tregs) among $\mathrm{CD}^{+}{ }^{+} \mathrm{T}$ cells (middle), and total $\mathrm{CD}^{+} \mathrm{T}$ cells among TCR $\alpha \beta^{+}$cells (right). Data are expressed as mean +/- SEM of individual mice $(n=9-15)$. Significant $p$ values as indicated [student's test $(\mathbf{A}-\mathbf{C})$ ].

Figure 6. TCR signaling is not essential for CD4-IEL maintenance.

(A-F) Flow cytometry analysis of intestinal epithelium (IE) of 8-22 week-old E8, ${ }^{\mathrm{WT}}$ (Trac)

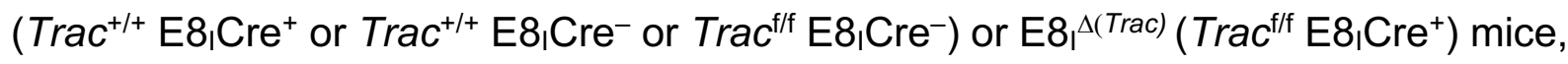
grouped by age as indicated. (A) Representative dot plots of surface CD8 $\alpha$ and TLTetramer among $\mathrm{CD}^{+} \mathrm{T}$ cells in $\mathrm{E} 8 \mathrm{I}^{\mathrm{WT}(T r a c)}$ (left) or $\mathrm{E}^{\mathrm{A}}{ }^{\Delta(T r a c)}$ (right) mice. (B) Frequency of CD4-IELs (CD8 $\alpha^{+} \mathrm{TL}^{-T^{2}}$ tramer $\left.{ }^{+}\right)$among $\mathrm{CD} 4^{+} \mathrm{T}$ cells in $\mathrm{E} 8 \mathrm{I}^{\mathrm{WT}(\mathrm{Trac})}$ and $\mathrm{E} 8 \mathrm{I}^{\Delta(\mathrm{Trac})}$ mice. (C, D) Frequency of proliferation (measured by EdU incorporation) of CD4 ${ }^{+} \mathrm{CD} 8 \alpha^{-}$ 
Foxp3- cells (Tconv) (C) among cells with or without surface TCR expression (D). Mice were injected with Edu 16 and 4 hours prior to analysis. (E, F) Frequencies of IFN $\gamma(\mathbf{E})$ and Gzmb (F) production upon PMA/lonomycin ex-vivo stimulation among CD4-IELs. (G-I) Bulk RNA-sequencing was performed on TCR $\beta^{+}$CD4-IELs from E8, ${ }^{\text {WT(Trac) }}$ and TCR $\beta^{-}$CD4-IELs from $E 8^{\Delta(\text { Trac })}$ mice ( $n=3$ per group). Volcano plot of differentially expressed genes between indicated populations $(p<0.05$, in color) $(\mathbf{G})$, selected differentially-enriched gene ontology (GO) pathways between groups $(\mathbf{H})$, and gene set enrichment analysis (GSEA) of CD4-IEL program as defined by the top differentiallyexpressed genes in the CD4-IEL cluster in our single cell RNA-Sequencing from Figure $2(\mathbf{I}) .(\mathbf{J}, \mathbf{K})$ Flow cytometry analysis of bone marrow chimeras in sub-lethally irradiated Rag $1^{-/-}$hosts reconstituted with $1 / 1$ ratio of WT CD45.1 and E8/ ${ }^{\Delta(T r a c)}$ CD45.2 cells, analyzed 12-16 weeks after reconstitution. Representative dot plots and histograms (J) and frequency $(\mathbf{K})$ of WT CD45.1 (red) versus $E 8^{\Delta(\text { Trac) }}$ CD45.2 (blue) among non- $\alpha \beta T$ cells (includes $\gamma \delta$ T cells and non-T cells), natural IELs (nIEL, CD4-CD8 $\alpha \alpha^{+}{ }^{+} D 8 \beta^{-}{ }^{-T L}-$ Tetramer $\left.{ }^{+}\right)$, CD8-IELs (CD4-CD8 $\alpha \alpha^{+} \mathrm{CD} 8 \beta^{+} \mathrm{TL}^{-}$Tetramer $\left.^{+}\right)$, and CD4-IELs in the IE. Bottom panels, representative histograms of surface TCR $\beta$ levels in WT CD45.1 (red line) and $\mathrm{E} 8 \mathrm{I}^{\Delta(\text { Trac })} \mathrm{CD} 45.2$ (blue line) of indicated cell populations. Frequency data are expressed as mean $+/$ - SEM (B-F). Significant $p$ values as indicated [student's $t$ test (B, C, E, F) or one-way ANOVA and Bonferroni (D)]. n=10-16 (B), n=4-14 (C, D), n=4-6 (E, F) and $n=12(K)$. 


\section{Methods}

\section{Animals}

Animal care and experimentation were consistent with NIH guidelines and were approved by the Institutional Animal Care and Use Committee at the Rockefeller

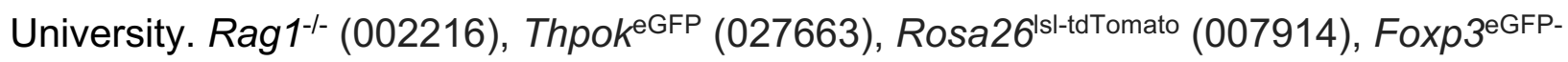
CreERT2 (016961), CD45.1(B6.SJL Ptprc ${ }^{a}$, 002014), Nr4a1EGFP/Cre (Nur77GFP, 016617), Foxp3 $3^{\text {IRES-mRFP }}$ (008374), OX40 IRES-Cre $(012839)$ mice were purchased from Jackson Laboratories and housed in our facility. Trac f/f mice were kindly provided by A. Rudensky (MSKCC). Villin CreERT2 mice were generated by (el Marjou et al., 2004) and

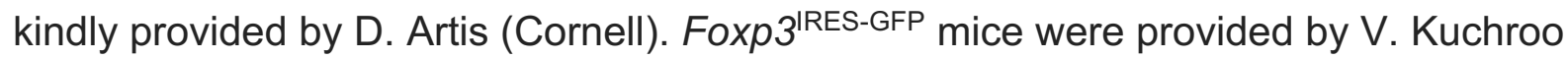
(Harvard) and $H 2-A b 1^{f / f}$ mice were provided by M. Nussenzweig (Jax 013181). E8, Cre were kindly provided by I. Taniuchi (Jax 008766). Several of these lines were interbred in our facilities to obtain the final strains described elsewhere in the text. Genotyping was performed according to the protocols established for the respective strains by Jackson Laboratories or by donor investigators. Mice were maintained at the Rockefeller University animal facility under specific pathogen-free (SPF) conditions.

\section{Antibodies and additional flow cytometry reagents}

Fluorescent dye-conjugated antibodies were purchased from BD Biosciences, Biolegend or Ebioscience (Thermofisher). The following clones were used: anti-

CD45.1, A20; anti-Foxp3, FJK-16s; anti-CD4, RM4-5; anti-CD19, eBio1D3; anti-IFN- $\gamma$, 
XMG1.2; anti-CD45.2, 104; anti-CD8 $\alpha, 53-6.7$; anti-CD8 $\beta$, YTS 156.7.7; anti-CD44, IM7; anti-I-A/I-E, M5/114.15.2; anti-CD45, 30-F11; anti-Granzyme B, NGZB; antiCD103, 2E7; anti-CD62L, MEL-14; anti-EpCAM, G8.8; anti-TCR $\beta$, H57-597; antiTCR $\gamma \delta$, eBioG23. Live/dead fixable dye Aqua and Edu (ThermoFisher Scientific) were used according to manufacturer's instructions. TL-Tetramer was obtained from $\mathrm{NIH}$ tetramer facility.

\section{Isolation of intestinal T cells}

Intraepithelial and lamina propria lymphocytes were isolated as previously described (Bilate et al., 2016; Reis et al., 2013). Briefly, small intestines were harvested and washed in PBS and 1mM dithiothreitol (DTT) followed by $30 \mathrm{mM}$ EDTA. Intraepithelial cells were recovered from the supernatant of DTT and EDTA washes and mononuclear cells were isolated by gradient centrifugation using Percoll. Lymphocytes from lamina propria were obtained after collagenase digestion of the tissue. Single-cell suspensions were then stained with fluorescently-labeled antibodies for $25 \mathrm{~min}$ at $4^{\circ} \mathrm{C}$ prior to downstream flow cytometry (analysis or sorting) as specified in figure legends.

\section{Flow cytometry and intranuclear/intracellular staining}

Flow cytometry data was acquired on an LSR-II flow cytometer (Becton Dickinson, USA) and analyzed using FlowJo software package (Tri-Star, USA). Intranuclear staining of Foxp3 was conducted using Foxp3 Mouse Regulatory T Cell Staining Kit (eBioscience, USA). For analysis of cytokine-secretion, IELs were plated in 48-well plates and incubated at $37^{\circ} \mathrm{C}$ with $100 \mathrm{ng} / \mathrm{mL}$ phorbol 12 -myristate 13 -acetate (PMA, Sigma) and $200 \mathrm{ng} / \mathrm{mL}$ ionomycin (Sigma) for 4 hours. Monesin ( $2 \mu \mathrm{M}$, Sigma) was 
added $1 \mathrm{~h}$ after PMA and ionomycin. Intracellular staining for IFN $\gamma$ and granzyme B was conducted in Perm/Wash buffer after permeabilization in Fix/Perm buffer (BD Pharmingen, USA) according to kit instructions.

\section{Staining Strategy}

For analysis of all $\Delta T r a c$ strains (and their controls), the following gating strategy was utilized to examine $\mathrm{CD}^{+} \mathrm{T}$ cells: single live lymphocytes (based on size and live/dead stain), $\mathrm{CD} 45^{+}, \mathrm{TCR} \gamma \delta^{-}$, intracellular $\mathrm{TCR} \beta^{+}, \mathrm{CD} 8 \beta^{- \text {llow }}, \mathrm{CD} 4^{+}$. For single-cell sorting of cells subjected to scTCRseq the following gating strategy was used: single live lymphocytes, CD45 ${ }^{+}, \mathrm{TCR} \gamma \delta^{-}, \mathrm{TCR}^{+}, \mathrm{CD} 8 \beta^{- \text {llow }}, \mathrm{CD} 4^{+}, \mathrm{Tomato}^{+/-} \mathrm{CD} 8 \alpha^{+/-}$

For sorting of cells subjected to bulk RNAseq we used single live lymphocytes CD45 ${ }^{+}$, $\mathrm{TCR} \gamma \delta^{-}, \mathrm{TCR}^{+/-}, \mathrm{CD} 8 \beta^{+/-}, \mathrm{CD} 4^{+/-}, \mathrm{TL}^{-}$Tetramer $^{+/-} \mathrm{CD} 8 \alpha^{+/-}$as indicated elsewhere in the text. For sorting of cells subjected to $10 \mathrm{X}$ Genomics, we gated on single live lymphocytes CD45 ${ }^{+} \mathrm{TCR} \gamma \delta^{-}, \mathrm{TCR} \beta^{+}, \mathrm{CD} 8 \beta^{- \text {llow }}, \mathrm{CD} 4^{+}$, Tomato $^{+/}$. IEL and Treg populations were confirmed by post-sort staining for surface CD8 $\alpha$ and intranuclear Foxp3, respectively.

\section{Edu treatment and Detection}

$1 \mathrm{mg}$ EdU was injected intravenously at $5 \mathrm{mg} / \mathrm{mL}$ in PBS 16 and 4 hours prior to analysis.

Detection was performed using the Click-iT ${ }^{\mathrm{TM}}$ Plus EdU Flow Cytometery Assay kit (Thermo Fisher Scientific, C10632), according to manufacturer's instructions. 


\section{Tamoxifen treatment}

Tamoxifen (Sigma) was dissolved in corn oil (Sigma) and 10\% ethanol and shaking at $37^{\circ} \mathrm{C}$ for $30 \mathrm{~min}-1 \mathrm{~h}$. Five doses of Tamoxifen (1mg/dose) was administered to

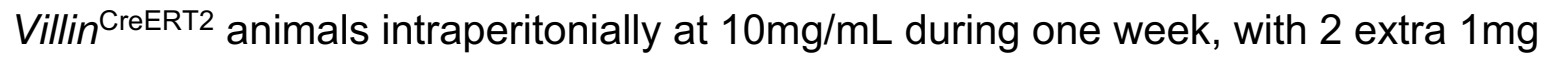
boosts 3 days apart 2 weeks before analysis, when analysis was more than 4 weeks after initial dosing, as indicated in figure legends. Four doses of Tamoxifen (5mg/dose) were administered to Foxp $3^{\text {GGFP-CreERT2 }}$ animals intragastrically 3 times 2 days apart in the first week, and then 2 times ( 3 days apart) every other week up to 2 weeks before analysis as indicated in figure legends. Unless otherwise noted, time between first tamoxifen administration and read-out was 10 weeks.

\section{Generation of mixed bone marrow chimeras}

Bone marrow cells were harvested from WT CD45.1 or Trac $^{\mathrm{f} / \mathrm{f}} \mathrm{E} 8 \mathrm{I}^{\mathrm{Cre}} \mathrm{CD} 45.2$ donors and depleted of T cell precursors using CD90.2 beads (Miltenyi) according to manufacturer's instructions. An equal mix of $5 \times 10^{6}$ total cells from WT CD45.1 and Trac $^{\mathrm{f} / \mathrm{f}} \mathrm{E} \mathrm{B}^{\mathrm{Cre}}{ }^{\mathrm{CD}} \mathrm{C} 4.2$ donors was intravenously injected into sub-lethally irradiated (6 Gy) Rag 1/-- hosts. Mice were analyzed 12-16 weeks after reconstitution.

\section{Single-cell TCR sequencing}

Single cells were sorted using a FACS Aria into 96-well plates containing $5 \mu \mathrm{L}$ of lysis buffer (TCL buffer, Qiagen 1031576) supplemented with 1\% $\beta$-mercaptoethanol) and frozen in $-80^{\circ} \mathrm{C}$ prior to RT-PCR. RNA and RT-PCRs for TCR $\alpha$ and TCR $\beta$ were prepared as previously described (Dash et al., 2011). PCR products for TCR $\alpha$ and 
TCR $\beta$ were either subjected to Sanger sequencing or multiplexed with barcodes and subjected to MiSeq sequencing (Han et al., 2014) using True Seq Nano kit (Illumina). For Miseq data, Fastaq files were de-multiplexed and paired-end sequences assembled using PANDAseq (Masella et al., 2012) and FASTAX toolkit.

Demultiplexed and collapsed reads were assigned to wells according to barcodes. Fasta files from both Sanger and Miseq sequences were aligned and analyzed on IMGT (imgt.org/HighV-QUEST) (Brochet et al., 2008). Cells with identical TCR $\beta$ CDR3 nucleotide sequences were considered as the same clones. Clonality was confirmed by sequencing TCR $\alpha$ of the expanded clones as assessed by TCR $\beta$ sequencing.

\section{Bulk RNAseq library preparation and analysis}

Sorted cells (300-800 cells) were lysed in a guanidine thiocyanate buffer (TCL buffer, Qiagen) supplemented with $1 \% \beta$-mercaptoethanol. RNA was isolated by solid-phase reversible immobilization bead cleanup using RNAClean XP beads (Agentcourt, A63987), reversibly transcribed, and amplified as described (Trombetta et al., 2014). Uniquely barcoded libraries were prepared using Nextera XT kit (Illumina) following manufacturer's instructions. Sequencing was performed on an Illumina NextSeq550. Raw fastq files were pseudomapped against the mouse transcriptome (gencode M23) using the kallisto (v0.46) software (Bray et al., 2016). Transcript quantification was processed using the sleuth (v0.30) package for R (Pimentel et al., 2017). Shortly, we modeled batch effect and our experimental design using the sleuth_fit function and detected differentially expressed genes between all groups by the likelihood ratio test 
(Irt). When detecting significantly expressed genes between sample pairs, we used the wald-test function. Detected genes in the Irt and wald-test were used in downstream analysis if the minimum false discovery rate threshold of 0.05 and $1 \log 2$ fold-change was reached. GSEA analysis was performed by using gene sets in gmt format and a full pre-ranked gene list by log2 fold-change between two groups as input for the fgsea package/R (Korotkevich et al., 2019). Gene ontology (GO) analysis was executed by comparing all detected genes as our background and the lists of differentially expressed genes against the biological processes gene sets by using the package for $\mathrm{R}$ topGO (Alexa and Rahnenfuhrer, 2019; Carlson M, 2019).

\section{Single cell RNAseq library preparation}

IELs were sorted, counted for viability and immediately subjected to library preparation. The scRNA-seq and scTCR-seq libraries were prepared using the 10x Single Cell Immune Profiling Solution Kit, according to the manufacturer's instructions at the Genomics core of Rockefeller University. The scRNA libraries were sequenced on an Illumina NextSeq550 to a minimum sequencing depth of 50,000 reads per cell using read lengths of $26 \mathrm{bp}$ read $1,8 \mathrm{bp}$ i7 index, $98 \mathrm{bp}$ read 2 . The single-cell TCR libraries were sequenced on an Illumina NextSeq550 to a minimum sequencing depth of 5,000 reads per cell using read lengths of 150 bp read 1,8 bp i7 index, 150 bp read 2 .

\section{Data processing of single cell RNAseq and single cell TCRseq libraries}

Raw fastq files derived from our RNA-seq libraries were processed with cellranger count (v3.1.0) using the 10x Genomics prebuilt mouse reference (v3.0.0 mm10). Our libraries 
were processed independently and merged into a single experiment at the analysis level using Seurat (v3.1.1) (Stuart et al., 2019). Quality control was performed by removing cells with high (> 5\%) mitochondrial UMI content. Cells having more than 4000 or less than 200 genes were excluded from our analysis. TCR contigs and annotation were performed with the Cellranger vdj workflow from 10x Genomics and the prebuild mouse reference ( $\mathrm{v} 3.1 .0 \mathrm{~mm} 10)$. Paired TCR clonotypes were defined by the V, (D), J and CDR3 nucleotide composition for alpha and beta chains. Cells in which only one of the TCR sequences was recovered were excluded from the paired TCR clonal composition analysis. TCR clonotype sharing was assigned to cells expressing identical V, (D), J, and CDR3 nucleotide and amino acid sequences.

Further processing and statistical analysis were performed using various $\mathrm{R}$ packages as described (RCoreTeam, 2019).

\section{Single cell RNAseq normalization and statistical analysis}

The raw UMI counts were normalized by applying a regression model with negative binomial error distribution, available through the SCTransform function in the Seurat (v3.1.1) package (Hafemeister and Satija, 2019). The top 3000 variable genes were first used for dimensional reduction by PCA using the scaled data. The first 30 principal components were further used on the clustering algorithm and UMAP embedding for two dimensional visualization by using the Seurat workflow (Hafemeister and Satija, 2019; Stuart et al., 2019). 


\section{Diffusion map and pseudotime analysis}

To infer cell differentiation trajectories based on the expression data, we used a diffusion map algorithm adapted for sc-RNAseq analysis and implemented through the package destiny (Angerer et al., 2016). Normalized values were used as input for the Diffusion Map function. Cells were ordered based on the first diffusion component. To visualize lineage differentiation within our UMAP embedding and find differentially expressed genes over pseudotime, we used the slingshot package (Street et al., 2018).

\section{Statistical Analyses}

Statistical analysis was carried out using GraphPad Prism v.8. Flow cytometry analysis was carried out using FlowJo software. Data in graphs show mean +/- SEM and $p$ values $<0.05$ were considered significant. Repertoire diversity was analyzed by the Chao1 index and by Diversity 50 (D50). The Chao1 index (Chao, 1984), a measure of alpha diversity, was calculated using EstimateS software (Colwell et al., 2012). Diversity 50 (D50) was calculated on Excel as the fraction of dominant clones that account for the cumulative $50 \%$ of the total paired CDR3s identified in each UMAP cluster. CDR3 similarity (TCR sharing) was calculated using the Morisita-horn overlap index by using the divo package (Rempala and Seweryn, 2013). GraphPadPrism v.8 was used for graphs and Adobe Illustrator 2019 used to assemble and edit figures. 


\section{Supplementary Table Titles}

Table S1. Top genes per UMAP cluster

Table S2. Clonotypes per UMAP cluster

\section{Supplementary Figure Legends}

Figure S1 (related to Fig.1; CD4-IELs are clonally expanded with decreased TCR diversity).

(A, B) Foxp $3^{\text {eGFP-Cre-ERT2 }} \times$ Rosa26 $^{\text {Is-tdTomato }} \times$ Foxp3 $3^{\text {IRES-GFP }}$ (iFoxp3 ${ }^{\text {Tom }}$ Foxp3 ${ }^{\text {GFP }}$ ) mice were treated with tamoxifen for 10 weeks, and $\mathrm{CD} 4^{+} \mathrm{T}$ cells from mesenteric lymph nodes ( $\mathrm{mLN}$ ), lamina propria (LP) and intestinal epithelium (IE) were sorted as follows: $\mathrm{CD}^{+}$Conventional (Tconv; GFP-Tomato-CD8 $\alpha^{-}$), regulatory T cells (Treg; $\mathrm{GFP}^{+}$or Tomato $\left.{ }^{+} \mathrm{CD} 8 \alpha^{-}\right)$, ex-Treg CD4-IEL $\left(\right.$Tomato $\left.^{+} \mathrm{CD} 8 \alpha^{+}\right)$and CD4-IEL (GFP-TomatoCD $8 \alpha^{+}$). TCR $\beta$ (and TCR $\alpha$ of expanded TCR $\beta$ clones) were sequenced via the MiSeq platform. (A) Representative dot plot of $\mathrm{GFP}^{+}$(green), tdTomato ${ }^{+}$(red) and doublenegative (grey) $\mathrm{CD} 4^{+} \mathrm{T}$ cells in the IE (left) and their corresponding CD8 $\alpha$ expression (histogram, right). (B) Representative nucleotide sequence alignment of TCR $\beta$ CDR3 of 2 expanded shared clones. (C) Dot plot depicting CD8 $\alpha$ and tdTomato expression by intraepithelial $\mathrm{CD}^{+}{ }^{\mathrm{T}} \mathrm{T}$ cells of an iFoxp3 ${ }^{\text {Tom }}$ mouse. Sorted Tregs (Tomato ${ }^{+} \mathrm{CD} 8 \alpha^{-}$), exTreg CD4-IELs $\left(\right.$ Tomato $\left.^{+} \mathrm{CD} 8 \alpha^{+}\right)$and CD4-IELs (Tomato-CD8 $\left.\alpha^{+}\right)$indicated by red boxes were sequenced by Sanger sequencing. (D) TCR $\beta$ clonal diversity of indicated IE populations. Each slice represents a distinct TCR $\beta$ CDR3. Colored clones represent sharing between populations. White slices represent unique clones and grey-scale 
slices represent expanded clones at indicated numbers. TCR $\alpha$ of expanded and/or shared clones were sequenced to confirm clonality.

Figure S2 (related to Fig.2; Clonal distribution of intraepithelial CD4 ${ }^{+} \mathrm{T}$ cells follows the single-cell trajectories).

(A-F) iFoxp3 ${ }^{\text {Tom }}$ mice were treated with tamoxifen for 10 weeks, and Tomato+ (library 1) and Tomato $^{-}$(library 2) $\mathrm{CD}^{+}{ }^{+} \mathrm{T}$ cells from the intestinal epithelium (IE) were sorted for scRNAseq using 10X Genomics platform. (A) Surface CD8 $\alpha$ and intranuclear Foxp3 expression of sequenced CD4 ${ }^{+}$Tomato $^{+}$(red) and Tomato ${ }^{-}$(black) cells. (B) Number of sequenced genes (left) and RNA molecules (middle) per cluster and percent of mitochondrial DNA (right) per UMAP cluster. (C) Expression levels of Foxp3 (red), Cd8a (green), or both (yellow) by all analyzed cells. (D) Expression levels of Sell by analyzed cells. (E) 2D volcano plot comparing clusters 5(RE-Treg), 3 (Treg) and 1 (Treg-like). (F) Proportion of cells per UMAP cluster from library 1 (Tomato ${ }^{+}$, red) and library 2 (Tomato-, blue). (G) Total number of cells with paired $\alpha \beta$ TCR sequences (grey) and total number of clones (green) within each UMAP cluster. (H) Normalized Morisita index (top right) and number of shared clones (bottom left) of paired $\alpha \beta T C R$ per UMAP cluster among tomato- cells.

Figure S3 (related to Fig.3; Intraepithelial CD4 ${ }^{+} \mathrm{T}$ cell subsets show an inverse correlation between TCR signaling and IEL program).

(A-C) Nur77-GFP expression levels by indicated cell types from Nur77 ${ }^{\text {GFP }}$ Foxp $3^{\text {RFP }}$ double-reporter mice. (A) Nur77 ${ }^{\text {GFP }}$ expression among CD4 ${ }^{+}$Foxp3 ${ }^{+}$regulatory T cells 


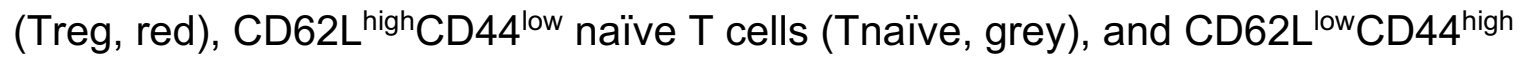
Foxp3- activated T cells (Tact, blue) in the mesenteric lymph nodes $(\mathrm{mLN}) .(\mathbf{B})$ Nur77 ${ }^{\text {GFP }}$ expression among Foxp3 ${ }^{+}$Tregs in the intestinal epithelium (IE, red) and $\mathrm{mLN}$ (blue). (C) Nur77 ${ }^{\mathrm{GFP}}$ expression among TCR $\gamma \delta$-IELs (red), CD8 $\alpha \alpha^{+} \mathrm{CD} 8 \beta^{-} \mathrm{CD} 4^{-} \mathrm{TCR} \alpha \beta^{+}$ natural IELs (nIEL, blue) and CD8 $\alpha \alpha^{+}$CD8 $\beta^{+}$TCR $\alpha \beta^{+}$IELs (CD8-IEL, grey) in the small intestine epithelium.

Figure S4 (related to Fig.4; TCR signaling is required for CD4-IEL differentiation). (A-C) Flow cytometry analysis of iFoxp3 $3^{\text {TomWt(Trac) }}\left(\right.$ Trac $\left.^{+/+} \mathrm{iFoxp}^{\text {Tom }}\right)$ or iFoxp3 $3^{\text {Tom } \Delta(\text { Trac })}$ $\left(\right.$ Trac $^{\mathrm{fff}} \mathrm{i}$ Foxp3 ${ }^{\text {Tom }}$ ) mice 8-12 weeks after tamoxifen administration. (A) Representative dot plots (left) for intracellular TCR $\beta$ and Foxp3, or histograms (right) of surface TCR $\beta$ expression among tomato ${ }^{+}$Foxp $^{+}$Tregs (red) and tomato ${ }^{+}$Foxp3 $^{-} \mathrm{CD}^{+}{ }^{+} \mathrm{T}$ cells (blue) in the intestinal epithelium (IE, top), lamina propria (LP, middle) and mesenteric lymph nodes (mLN, bottom). (B) Frequencies of surface TCR $\beta$-expressing cells among Foxp3 ${ }^{+}$ or Foxp3- among tomato $^{+} \mathrm{CD} 4^{+} \mathrm{T}$ cells from iFoxp3 ${ }^{\text {Tom } \Delta(\text { Trac) }}$ IE (top), LP (middle) or $\mathrm{mLN}$ (bottom). (C) Frequency of CD8 $\alpha$-expressing CD4+ ${ }^{+}$(CD4-IEL) cells among tomato $^{-}$cells in the IE of iFoxp3 $3^{\text {TomWT(Trac) }}$ or iFoxp3 ${ }^{\text {Tom } \Delta(T r a c)}$ mice. (D-J) Flow cytometry analysis of cells isolated from the IE and $\mathrm{mLN}$ of 9-12 week-old OX40WT(Trac) $\left(\mathrm{Trac}^{+/+}\right.$

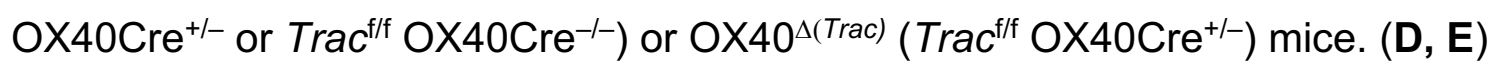
Frequencies of total CD4 ${ }^{+} \mathrm{T}$ cells $(\mathrm{D})$ and CD4-IELs $\left(\mathrm{CD} 8 \alpha^{+} \mathrm{TL}^{-}\right.$Tetramer $\left.^{+}\right)(\mathrm{E})$ among total $\mathrm{CD} 45^{+}$cells in the IE. (F-J) Frequencies of surface TCR $\beta$-expressing cells among $\mathrm{CD}^{+} \mathrm{T}$ cells $(\mathbf{F})$, Tregs $(\mathbf{G}), \mathrm{CD}^{+}$activated $\left(\right.$Tact, Foxp3-CD44 $\left.{ }^{\text {high }} \mathrm{CD} 62 \mathrm{~L}^{\text {low }}\right)(\mathbf{H})$ and CD4 ${ }^{+}$Naïve (Tnaïve, Foxp3-CD44 ${ }^{\text {low }}{ }^{-} D 62 L^{\text {high }}$ ) (I) cells in the mLN. (J) Histogram of 
surface TCR $\beta$ expression among Tregs (red), Tact (blue) and Tnaïve (grey) CD4 ${ }^{+}$T

cells in the $\mathrm{mLN}$. Data are expressed as mean + - SEM of individual mice $(\mathrm{n}=5-11)$.

Significant $p$ values as indicated [student's t test $(B-I)]$.

Figure S5 (related to Fig.5; MHCII expression by epithelial cells is required for CD4-IEL conversion).

(A-C) Flow cytometry analysis of the intestinal epithelium (IE) of iVillin WT(MHCII) (H2$A b 1^{+/+}$Villin ${ }^{\text {CreERT2+/- }}$ or $H 2-A b 1^{\text {f/f }}$ Villin $^{\text {CreERT2-/- }}$ or iVillin ${ }^{\Delta(M H C l l)}\left(H 2-A b 1^{\text {f/f }}\right.$ Villin $\left.^{\text {CreERT2+/+ }}\right)$

mice after tamoxifen administration. Geometric mean fluorescence intensity (gMFI) (left) and frequency (right) of MHCII expression by epithelial cells of 13-17 week-old mice 3-5 weeks after tamoxifen administration $(\mathbf{A})$ and of 21-22 week-old mice 5 weeks after tamoxifen administration (B). (C) Representative histogram of MHCll expression by $\mathrm{EpCAM}^{+}$epithelial cells in 20 week-old iVillin ${ }^{\mathrm{WT}(M H C I I)}$ (white) or iVillin ${ }^{\Delta(M H C l l)}$ (grey) mice 4 weeks after tamoxifen administration. Data are expressed as mean +/- SEM of individual mice $(n=5-14)$. Significant $p$ values as indicated [student's t test $(\mathbf{A}, \mathbf{B})$ ].

\section{Figure S6 (related to Fig.6; TCR signaling is not essential for CD4-IEL} maintenance).

(A-L) Flow cytometry analysis of 8-22 week-old E8,WT(Trac) $\left(\right.$ Trac $^{+/+}$E8ICre ${ }^{+}$or Trac $^{+/+}$

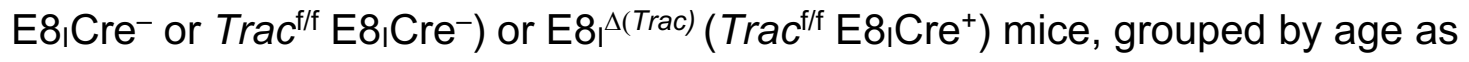
indicated. Frequencies of surface TCR $\beta$-expressing cells among CD8 $\alpha \beta$ cells $(\mathbf{A})$ and CD4 (B) T cells in the mesenteric lymph nodes (mLN). Frequency of CD8 $\alpha \beta$ T cells among total $\mathrm{CD} 45^{+}$cells (C) and intracellular TCR $\beta$-expressing T cells (D) in the mLN. 
Frequencies of CD8 $\alpha \beta(E)$ and natural IELs (nIEL, CD4-CD8 $\alpha \alpha^{+} \mathrm{CD} 8 \beta^{-}{ }^{-}{ }^{-}-$Tetramer $^{+}$)

(F) among CD45 $5^{+}$cells in the intestinal epithelium (IE). (G, H) Proliferation (EdU incorporation) of CD8-IELs $(\mathbf{G})$ or nIELs $(\mathbf{H})$ with or without surface TCR $\beta$ expression after EdU injection 16 and 4 hours prior to analysis. (I-L) Frequencies of IFN $\gamma(\mathbf{I}, \mathbf{K})$ and Gzmb (J, L) production upon PMA/lonomycin ex-vivo stimulation among CD8-IELs (I, J) and nIELs (K, L). (M-O) Bulk RNA-sequencing was performed on TCR ${ }^{+}$CD4-IELs, CD8-IELs and nIELs from E8, ${ }^{\text {WT(Trac) }}$ and TCR- CD4-IELs from E8, ${ }^{\Delta(T r a c)}$ mice. (M) Principal component analysis of indicated cell populations. $(\mathbf{N}, \mathbf{O})$ Volcano plots of differentially expressed genes between indicated populations ( $p<0.05$, in color) (top), and selected differentially-enriched gene ontology (GO) pathways between them (bottom). Data are expressed as mean $+/-$ SEM of individual mice. $(n=4-14)$. Significant $p$ values as indicated [student's t test (A-F, I-L) or one-way ANOVA and Bonferroni (G, H)]. $\mathrm{N}=10-16(\mathbf{A}-\mathbf{F}), \mathrm{n}=4-14(\mathbf{G}, \mathbf{H})$ and $n=4-6(\mathbf{I}-\mathbf{L})$. Sequencing data is $n=3$ mice per group (M-O). 


\section{References}

Alexa, A., and Rahnenfuhrer, J. (2019). topGO: Enrichment Analysis for Gene Ontology. R package version 2.24.0.

Angerer, P., Haghverdi, L., Buttner, M., Theis, F.J., Marr, C., and Buettner, F. (2016). destiny: diffusion maps for large-scale single cell data in R. Bioinformatics 32, 1241-1243.

Atarashi, K., Tanoue, T., Oshima, K., Suda, W., Nagano, Y., Nishikawa, H., Fukuda, S., Saito, T., Narushima, S., Hase, K., et al. (2013). Treg induction by a rationally selected mixture of Clostridia strains from the human microbiota. Nature 500, 232-236.

Bilate, A.M., Bousbaine, D., Mesin, L., Agudelo, M., Leube, J., Kratzert, A., Dougan, S.K., Victora, G.D., and Ploegh, H.L. (2016). Tissue-specific emergence of regulatory and intraepithelial T cells from a clonal T cell precursor. Sci Immunol 1, eaaf7471.

Biton, M., Haber, A.L., Rogel, N., Burgin, G., Beyaz, S., Schnell, A., Ashenberg, O., Su, C.W., Smillie, C., Shekhar, K., et al. (2018). T Helper Cell Cytokines Modulate Intestinal Stem Cell Renewal and Differentiation. Cell 175, 1307-1320 e1322.

Bray, N.L., Pimentel, H., Melsted, P., and Pachter, L. (2016). Near-optimal probabilistic RNAseq quantification. Nat Biotechnol 34, 525-527.

Brochet, X., Lefranc, M.P., and Giudicelli, V. (2008). IMGT/V-QUEST: the highly customized and integrated system for IG and TR standardized V-J and V-D-J sequence analysis. Nucleic Acids Res 36, W503-508.

Carlson M (2019). GO.db: A set of annotation maps describing the entire Gene Ontology. R package version 3.8.2.

Cervantes-Barragan, L., Chai, J.N., Tianero, M.D., Di Luccia, B., Ahern, P.P., Merriman, J., Cortez, V.S., Caparon, M.G., Donia, M.S., Gilfillan, S., et al. (2017). Lactobacillus reuteri induces gut intraepithelial CD4(+)CD8alphaalpha(+) T cells. Science 357, 806-810.

Chao, A. (1984). Nonparametric-Estimation of the Number of Classes in a Population. Scand J Stat 11, 265-270.

Cheroutre, H., and Lambolez, F. (2008). Doubting the TCR coreceptor function of CD8alphaalpha. Immunity 28, 149-159.

Cheroutre, H., Lambolez, F., and Mucida, D. (2011). The light and dark sides of intestinal intraepithelial lymphocytes. Nat Rev Immunol 11, 445-456. 
Colwell, R.K., Chao, A., Gotelli, N.J., Lin, S.Y., Mao, C.X., Chazdon, R.L., and Longino, J.T. (2012). Models and estimators linking individual-based and sample-based rarefaction, extrapolation and comparison of assemblages. J Plant Ecol 5, 3-21.

Cortez, V.S., Cervantes-Barragan, L., Song, C., Gilfillan, S., McDonald, K.G., Tussiwand, R., Edelson, B.T., Murakami, Y., Murphy, K.M., Newberry, R.D., et al. (2014). CRTAM controls residency of gut CD4+CD8+ T cells in the steady state and maintenance of gut CD4+ Th17 during parasitic infection. J Exp Med 211, 623-633.

Curotto de Lafaille, M.A., Lino, A.C., Kutchukhidze, N., and Lafaille, J.J. (2004). CD25- T cells generate CD25+Foxp3+ regulatory T cells by peripheral expansion. J Immunol 173, 7259-7268.

Dash, P., McClaren, J.L., Oguin, T.H., 3rd, Rothwell, W., Todd, B., Morris, M.Y., Becksfort, J., Reynolds, C., Brown, S.A., Doherty, P.C., and Thomas, P.G. (2011). Paired analysis of TCRalpha and TCRbeta chains at the single-cell level in mice. J Clin Invest 121, 288-295.

el Marjou, F., Janssen, K.P., Chang, B.H., Li, M., Hindie, V., Chan, L., Louvard, D., Chambon, P., Metzger, D., and Robine, S. (2004). Tissue-specific and inducible Cre-mediated recombination in the gut epithelium. Genesis 39, 186-193.

Ellmeier, W., Sunshine, M.J., Losos, K., Hatam, F., and Littman, D.R. (1997). An enhancer that directs lineage-specific expression of CD8 in positively selected thymocytes and mature T cells. Immunity 7, 537-547.

Fan, X., and Rudensky, A.Y. (2016). Hallmarks of Tissue-Resident Lymphocytes. Cell 164, 1198-1211.

Faria, A.M.C., Reis, B.S., and Mucida, D. (2017). Tissue adaptation: Implications for gut immunity and tolerance. J Exp Med 214, 1211-1226.

Guy-Grand, D., Cerf-Bensussan, N., Malissen, B., Malassis-Seris, M., Briottet, C., and Vassalli, P. (1991). Two gut intraepithelial CD8+ lymphocyte populations with different T cell receptors: a role for the gut epithelium in T cell differentiation. J Exp Med 173, 471-481.

Hafemeister, C., and Satija, R. (2019). Normalization and variance stabilization of single-cell RNA-seq data using regularized negative binomial regression. bioRxiv, 576827.

Han, A., Glanville, J., Hansmann, L., and Davis, M.M. (2014). Linking T-cell receptor sequence to functional phenotype at the single-cell level. Nat Biotechnol 32, 684-692.

Hogquist, K.A., and Jameson, S.C. (2014). The self-obsession of T cells: how TCR signaling thresholds affect fate 'decisions' and effector function. Nat Immunol 15, 815-823.

Ivanov, I.I., Atarashi, K., Manel, N., Brodie, E.L., Shima, T., Karaoz, U., Wei, D., Goldfarb, K.C., Santee, C.A., Lynch, S.V., et al. (2009). Induction of intestinal Th17 cells by segmented filamentous bacteria. Cell 139, 485-498. 
Korotkevich, G., Sukhov, V., and Sergushichev, A. (2019). Fast gene set enrichment analysis. bioRxiv, 060012.

Koyama, M., Mukhopadhyay, P., Schuster, I.S., Henden, A.S., Hulsdunker, J., Varelias, A., Vetizou, M., Kuns, R.D., Robb, R.J., Zhang, P., et al. (2019). MHC Class II Antigen Presentation by the Intestinal Epithelium Initiates Graft-versus-Host Disease and Is Influenced by the Microbiota. Immunity.

Ladinsky, M.S., Araujo, L.P., Zhang, X., Veltri, J., Galan-Diez, M., Soualhi, S., Lee, C., Irie, K., Pinker, E.Y., Narushima, S., et al. (2019). Endocytosis of commensal antigens by intestinal epithelial cells regulates mucosal T cell homeostasis. Science 363.

Lathrop, S.K., Bloom, S.M., Rao, S.M., Nutsch, K., Lio, C.W., Santacruz, N., Peterson, D.A., Stappenbeck, T.S., and Hsieh, C.S. (2011). Peripheral education of the immune system by colonic commensal microbiota. Nature 478, 250-254.

Leishman, A.J., Gapin, L., Capone, M., Palmer, E., MacDonald, H.R., Kronenberg, M., and Cheroutre, H. (2002). Precursors of functional MHC class I- or class II-restricted CD8alphaalpha(+) T cells are positively selected in the thymus by agonist self-peptides. Immunity 16, 355-364.

Levine, A.G., Arvey, A., Jin, W., and Rudensky, A.Y. (2014). Continuous requirement for the TCR in regulatory T cell function. Nat Immunol 15, 1070-1078.

Liu, X., Nguyen, P., Liu, W., Cheng, C., Steeves, M., Obenauer, J.C., Ma, J., and Geiger, T.L. (2009). T cell receptor CDR3 sequence but not recognition characteristics distinguish autoreactive effector and Foxp3(+) regulatory T cells. Immunity 31, 909-920.

Masella, A.P., Bartram, A.K., Truszkowski, J.M., Brown, D.G., and Neufeld, J.D. (2012). PANDAseq: PAired-eND Assembler for Illumina sequences. Bmc Bioinformatics 13.

Mayans, S., Stepniak, D., Palida, S.F., Larange, A., Dreux, J., Arlian, B.M., Shinnakasu, R., Kronenberg, M., Cheroutre, H., and Lambolez, F. (2014). alphabetaT cell receptors expressed by CD4(-)CD8alphabeta(-) intraepithelial T cells drive their fate into a unique lineage with unusual MHC reactivities. Immunity 41, 207-218.

McDonald, B.D., Bunker, J.J., Erickson, S.A., Oh-Hora, M., and Bendelac, A. (2015). Crossreactive alphabeta T Cell Receptors Are the Predominant Targets of Thymocyte Negative Selection. Immunity 43, 859-869.

McDonald, B.D., Bunker, J.J., Ishizuka, I.E., Jabri, B., and Bendelac, A. (2014). Elevated T cell receptor signaling identifies a thymic precursor to the TCRalphabeta(+)CD4(-)CD8beta(-) intraepithelial lymphocyte lineage. Immunity 41, 219-229.

McDonald, B.D., Jabri, B., and Bendelac, A. (2018). Diverse developmental pathways of intestinal intraepithelial lymphocytes. Nat Rev Immunol 18, 514-525. 
Miragaia, R.J., Gomes, T., Chomka, A., Jardine, L., Riedel, A., Hegazy, A.N., Whibley, N., Tucci, A., Chen, X., Lindeman, I., et al. (2019). Single-Cell Transcriptomics of Regulatory T Cells Reveals Trajectories of Tissue Adaptation. Immunity 50, 493-504 e497.

Moran, A.E., Holzapfel KI Fau - Xing, Y., Xing Y Fau - Cunningham, N.R., Cunningham Nr Fau Maltzman, J.S., Maltzman Js Fau - Punt, J., Punt J Fau - Hogquist, K.A., and Hogquist, K.A. (2011). T cell receptor signal strength in Treg and iNKT cell development demonstrated by a novel fluorescent reporter mouse. J Exp Med 208, 1279-1289.

Mucida, D., Husain, M.M., Muroi, S., van Wijk, F., Shinnakasu, R., Naoe, Y., Reis, B.S., Huang, Y., Lambolez, F., Docherty, M., et al. (2013). Transcriptional reprogramming of mature CD4(+) helper T cells generates distinct MHC class II-restricted cytotoxic T Iymphocytes. Nat Immunol 14, 281-289.

Mucida, D., Kutchukhidze, N., Erazo, A., Russo, M., Lafaille, J.J., and Curotto de Lafaille, M.A. (2005). Oral tolerance in the absence of naturally occurring Tregs. J Clin Invest 115, 1923-1933.

Panja, A., Goldberg, S., Eckmann, L., Krishen, P., and Mayer, L. (1998). The regulation and functional consequence of proinflammatory cytokine binding on human intestinal epithelial cells. Journal of immunology 161, 3675-3684.

Pimentel, H., Bray, N.L., Puente, S., Melsted, P., and Pachter, L. (2017). Differential analysis of RNA-seq incorporating quantification uncertainty. Nat Methods 14, 687-690.

RCoreTeam (2019). R: A Language and Environment for Statistical Computing. R Foundation for Statistical Computing.

Regnault, A., Cumano, A., Vassalli, P., Guy-Grand, D., and Kourilsky, P. (1994). Oligoclonal repertoire of the CD8 alpha alpha and the CD8 alpha beta TCR-alpha/beta murine intestinal intraepithelial T lymphocytes: evidence for the random emergence of T cells. J Exp Med 180, 1345-1358.

Regnault, A., Levraud, J.P., Lim, A., Six, A., Moreau, C., Cumano, A., and Kourilsky, P. (1996). The expansion and selection of $\mathrm{T}$ cell receptor alpha beta intestinal intraepithelial $\mathrm{T}$ cell clones. Eur J Immunol 26, 914-921.

Reis, B.S., Hoytema van Konijnenburg, D.P., Grivennikov, S.I., and Mucida, D. (2014). Transcription Factor T-bet Regulates Intraepithelial Lymphocyte Functional Maturation. Immunity 41, 244-256.

Reis, B.S., Rogoz, A., Costa-Pinto, F.A., Taniuchi, I., and Mucida, D. (2013). Mutual expression of the transcription factors Runx3 and ThPOK regulates intestinal CD4(+) T cell immunity. Nat Immunol 14, 271-280.

Rempala, G.A., and Seweryn, M. (2013). Methods for diversity and overlap analysis in T-cell receptor populations. J Math Biol 67, 1339-1368. 
Rocha, B., Vassalli, P., and Guy-Grand, D. (1991). The V beta repertoire of mouse gut homodimeric alpha CD8+ intraepithelial T cell receptor alpha/beta + lymphocytes reveals a major extrathymic pathway of T cell differentiation. J Exp Med 173, 483-486.

Sakaguchi, S., Vignali, D.A., Rudensky, A.Y., Niec, R.E., and Waldmann, H. (2013). The plasticity and stability of regulatory T cells. Nat Rev Immunol 13, 461-467.

Street, K., Risso, D., Fletcher, R.B., Das, D., Ngai, J., Yosef, N., Purdom, E., and Dudoit, S. (2018). Slingshot: cell lineage and pseudotime inference for single-cell transcriptomics. Bmc Genomics 19.

Stuart, T., Butler, A., Hoffman, P., Hafemeister, C., Papalexi, E., Mauck, W.M., Hao, Y.H., Stoeckius, M., Smibert, P., and Satija, R. (2019). Comprehensive Integration of Single-Cell Data. Cell 177, 1888-+.

Sujino, T., London, M., Hoytema van Konijnenburg, D.P., Rendon, T., Buch, T., Silva, H.M., Lafaille, J.J., Reis, B.S., and Mucida, D. (2016). Tissue adaptation of regulatory and intraepithelial CD4(+) T cells controls gut inflammation. Science 352, 1581-1586.

Trombetta, J.J., Gennert, D., Lu, D., Satija, R., Shalek, A.K., and Regev, A. (2014). Preparation of Single-Cell RNA-Seq Libraries for Next Generation Sequencing. Curr Protoc Mol Biol 107, 4 22 21-17.

Umesaki, Y., Okada, Y., Matsumoto, S., Imaoka, A., and Setoyama, H. (1995). Segmented filamentous bacteria are indigenous intestinal bacteria that activate intraepithelial lymphocytes and induce MHC class II molecules and fucosyl asialo GM1 glycolipids on the small intestinal epithelial cells in the ex-germ-free mouse. Microbiol Immunol 39, 555-562.

Wojciech, L., Szurek, E., Kuczma, M., Cebula, A., Elhefnawy, W.R., Pietrzak, M., Rempala, G., and Ignatowicz, L. (2018). Non-canonicaly recruited TCRalphabetaCD8alphaalpha IELs recognize microbial antigens. Sci Rep 8, 10848.

Xu, M., Pokrovskii, M., Ding, Y., Yi, R., Au, C., Harrison, O.J., Galan, C., Belkaid, Y., Bonneau, R., and Littman, D.R. (2018). c-MAF-dependent regulatory T cells mediate immunological tolerance to a gut pathobiont. Nature 554, 373-377.

Yamagata, T., Mathis, D., and Benoist, C. (2004). Self-reactivity in thymic double-positive cells commits cells to a CD8 alpha alpha lineage with characteristics of innate immune cells. Nat Immunol 5, 597-605.

Yang, Y., Torchinsky, M.B., Gobert, M., Xiong, H., Xu, M., Linehan, J.L., Alonzo, F., Ng, C., Chen, A., Lin, X., et al. (2014). Focused specificity of intestinal TH17 cells towards commensal bacterial antigens. Nature 510, 152-156. 
Zemmour, D., Zilionis, R., Kiner, E., Klein, A.M., Mathis, D., and Benoist, C. (2018). Single-cell gene expression reveals a landscape of regulatory $T$ cell phenotypes shaped by the TCR. Nature immunology 19, 291-301.

Zhou, X., Bailey-Bucktrout, S.L., Jeker, L.T., Penaranda, C., Martinez-Llordella, M., Ashby, M., Nakayama, M., Rosenthal, W., and Bluestone, J.A. (2009). Instability of the transcription factor Foxp3 leads to the generation of pathogenic memory T cells in vivo. Nat Immunol 10, 10001007. 
A was not certified by peer review) is the author/funder. All rights reserved. No reuse allowed without permission.

Figure 1

Clonality: Mouse 1 TCR $\beta$
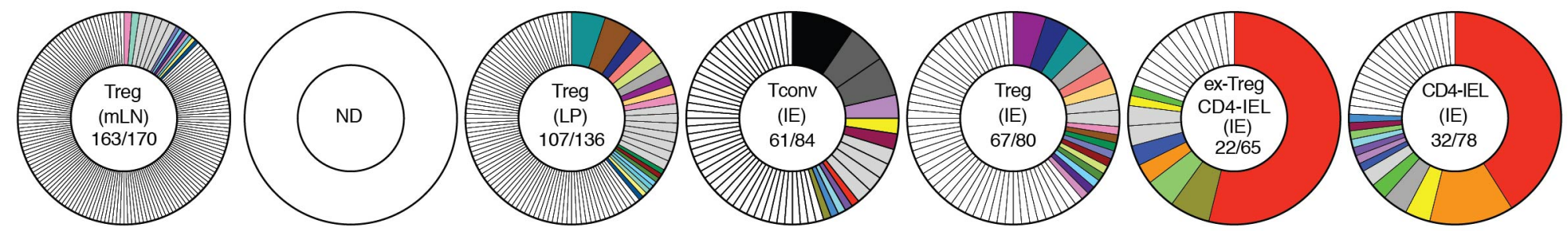

Clonality: Mouse 2 TCR $\beta$
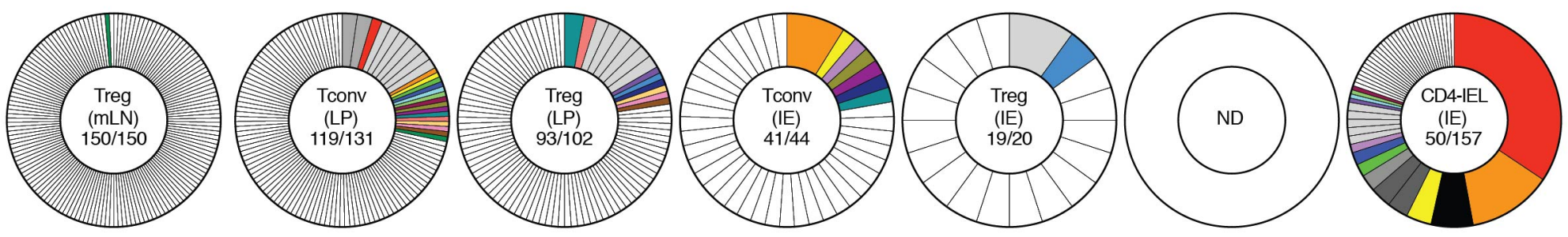

Sharing within mouse

$\square$ Unique clones

$\square 2 X$

$3 x$

$4 X$

$5 X$

$>5 X$

B

Mouse 1: TCR $\beta$ CDR3 Diversity

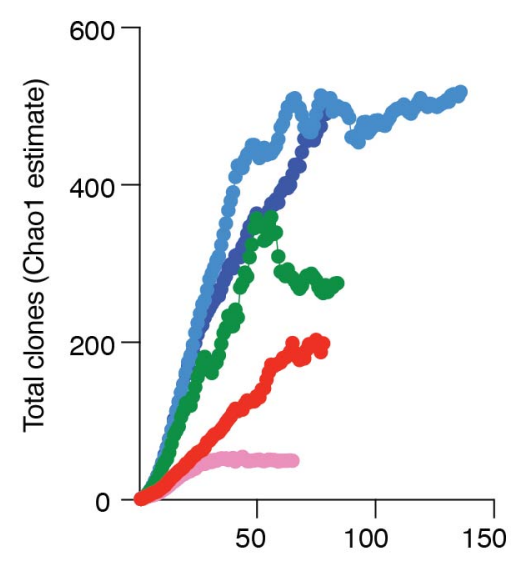

$\mathrm{N}^{\circ}$ of cells sampled

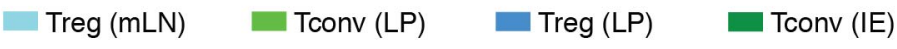

$$
\begin{aligned}
& \text { Treg (IE) ex-Treg CD4-IEL (IE) —CD4-IEL (IE) }
\end{aligned}
$$

Mouse 2: TCR $\beta$ CDR3 Diversity

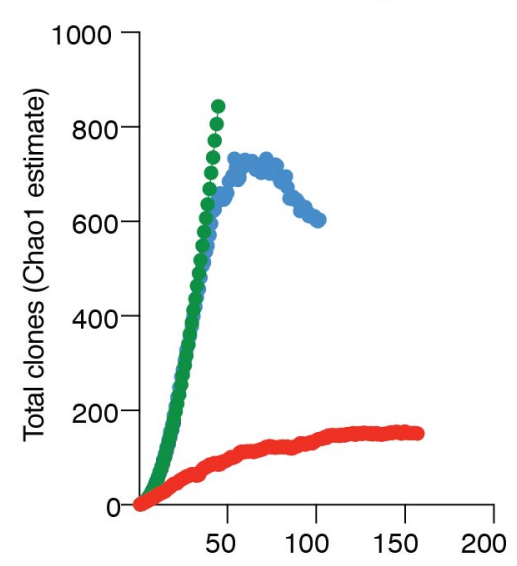

$\mathrm{N}^{\circ}$ of cells sampled

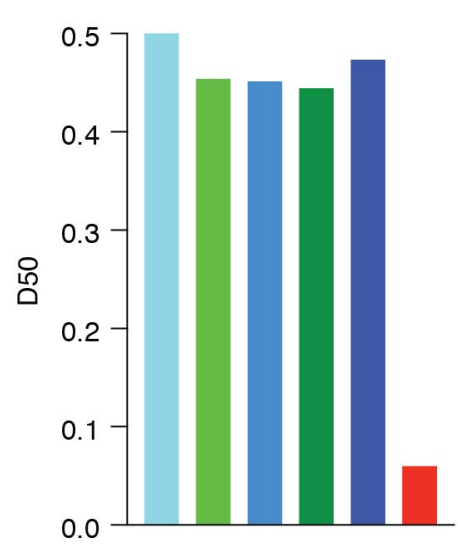

Population
C

Mouse 1: TCR $\beta$ CDR3

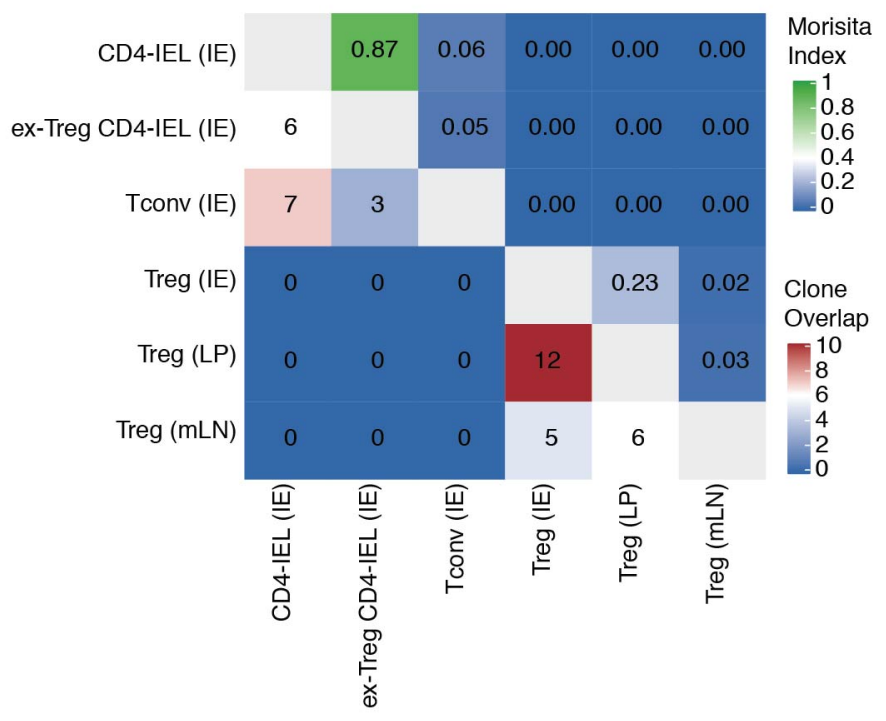

Mouse 2: TCR $\beta$ CDR3

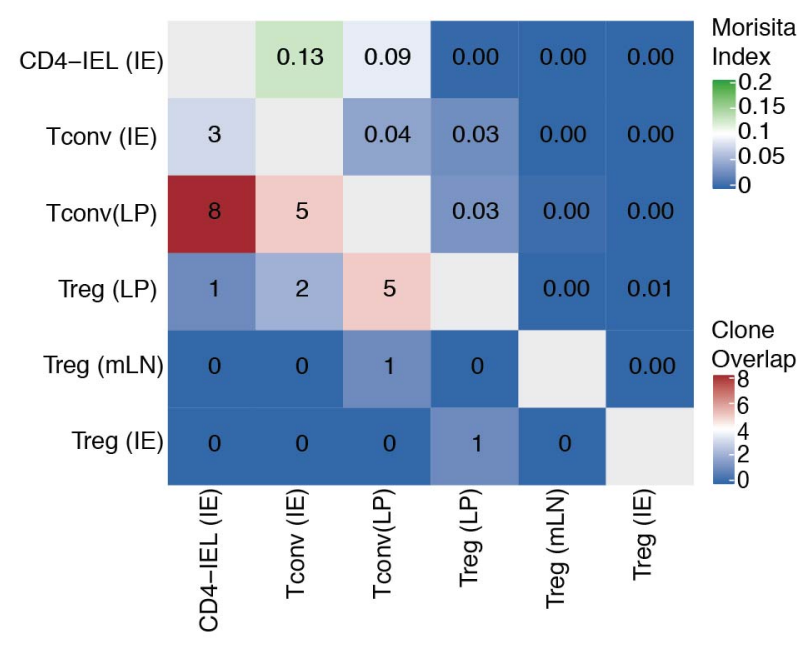


A bioRxiv preprint doi: https://doi.org/10.1101/2020.06.04.134510; this versigh posted June 5, 2020. The copyright holder for this preprint (whithigure 2
was not certified by peer review) is the author/funder. All rights reserved. No reuse allowed without permission.
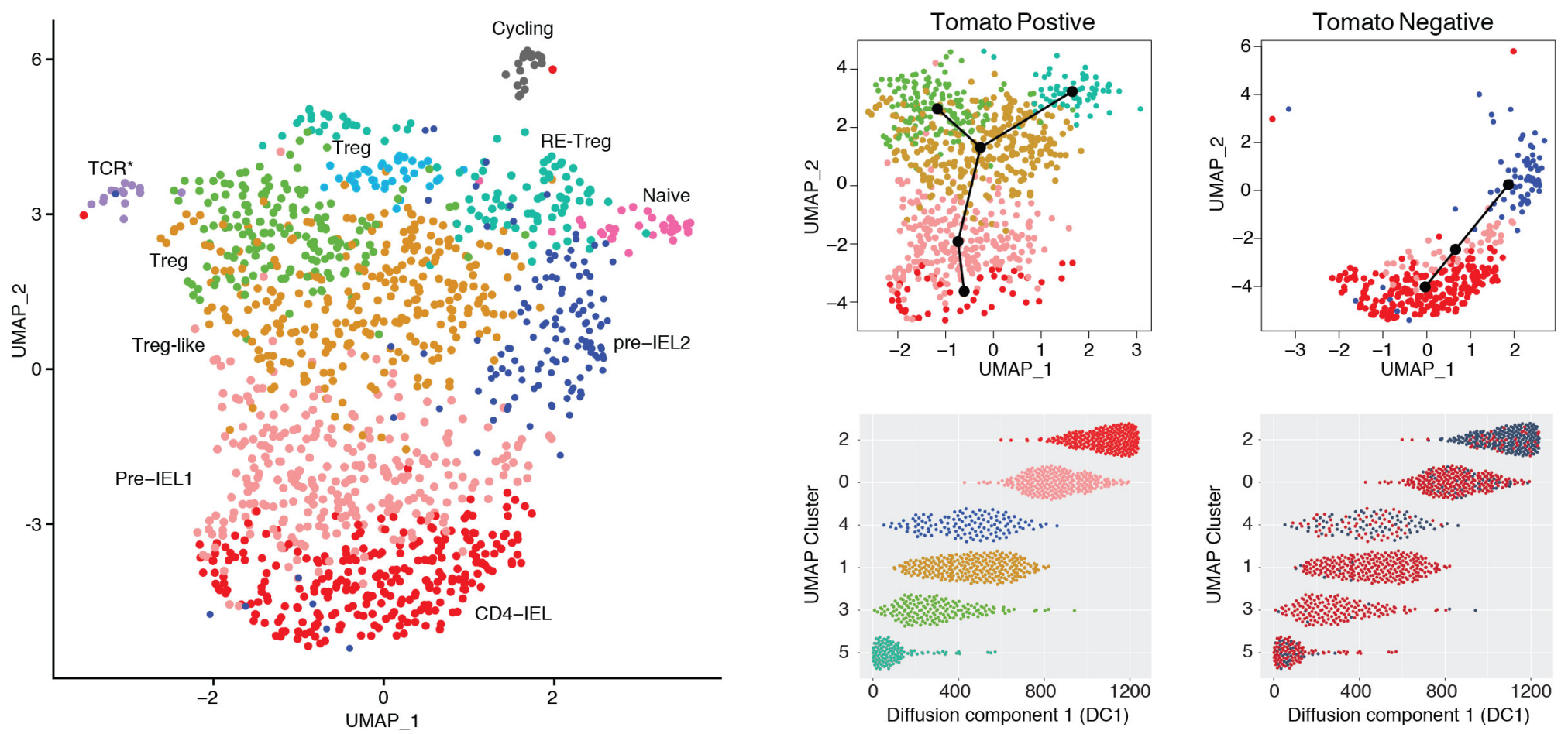
- 0_Pre-IEL1
1_Treg-like
2_CD4-IEL 3_Treg 4_P
- 7_Cycling $\bullet$ 3a_Treg $\left(\mathrm{TCR}^{\star}\right)$
5_RE-Treg
5a_RE-Treg (Naive*

C

D

E
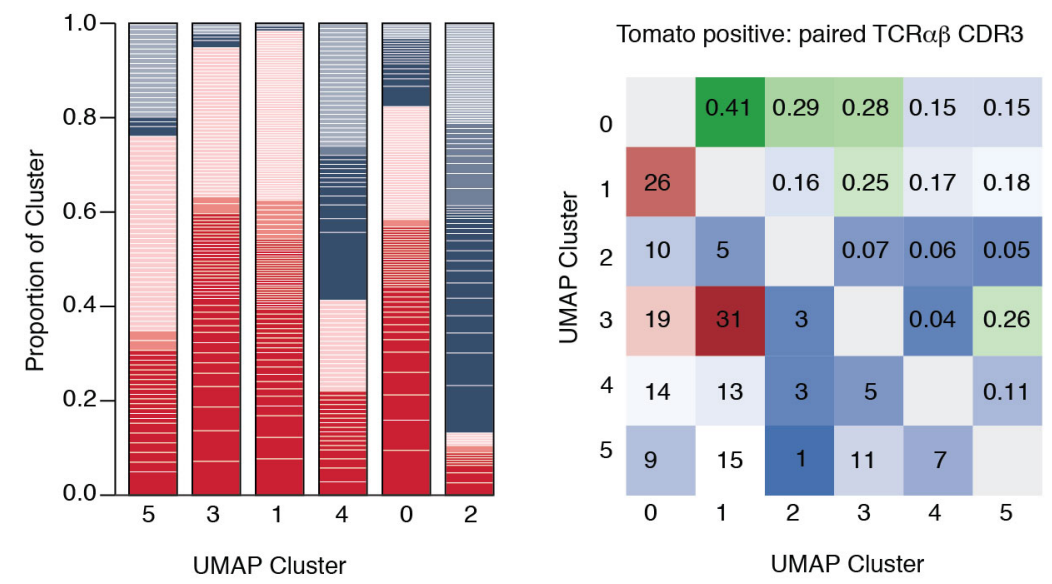

TP TN
$\square \quad \square$ Shared
$\square \quad \square$ Expanded within cluster
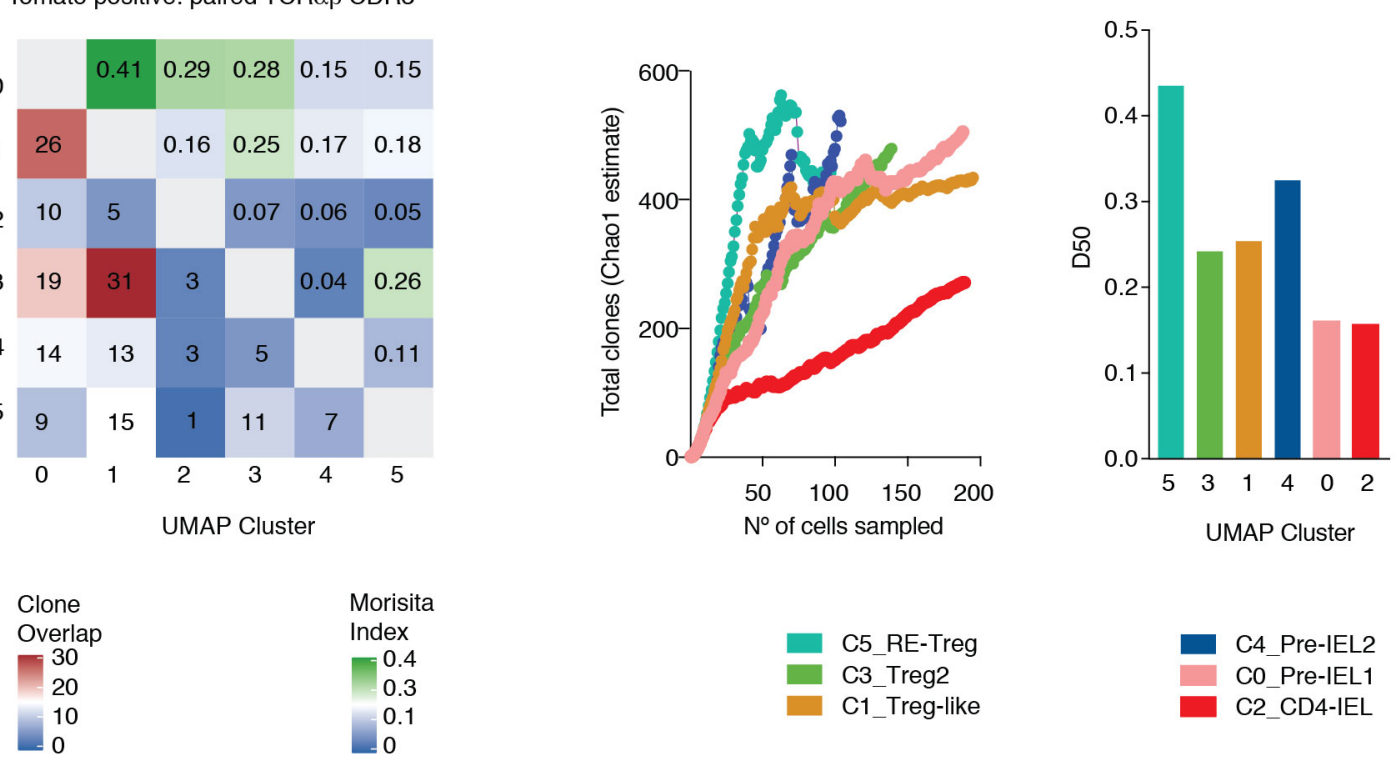

$\mathbf{F}$
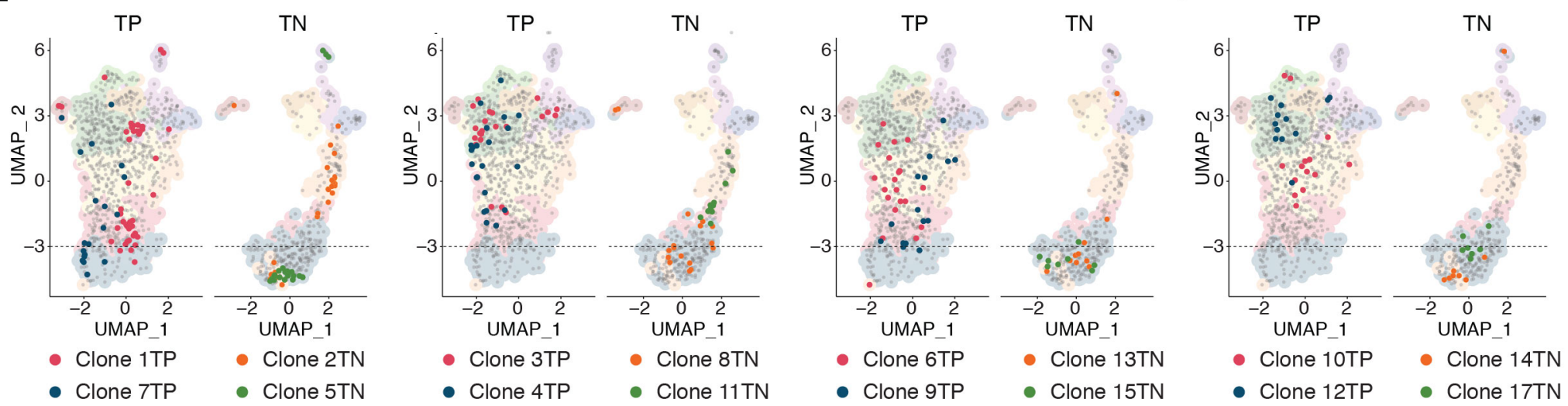
TCR Signaling/Co-stimulation
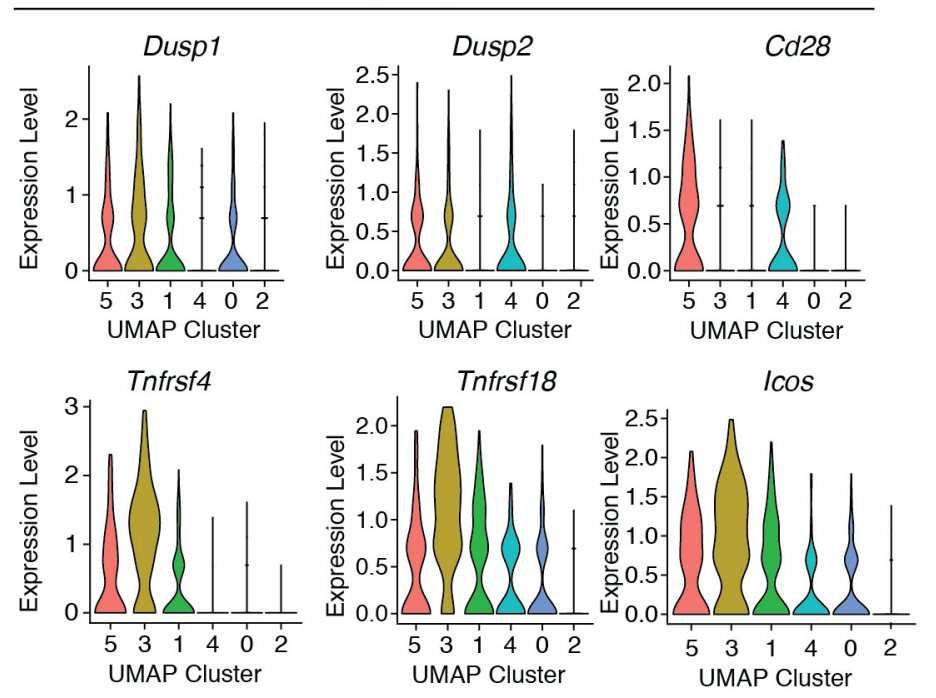

$$
\begin{array}{lll}
\text { UMAP Clusters } & & \\
\text { 5_RE-Treg } & \text { 3_Treg } & \text { 1_Treg-like } \\
\text { 4_Pre-IEL2 } & \text { 0_Pre-IEL1 } & \text { 2_CD4-IEL }
\end{array}
$$

B

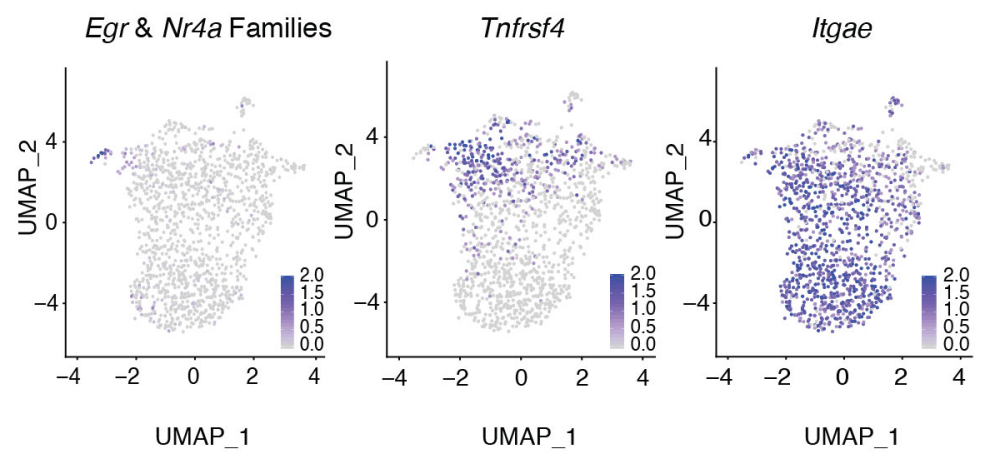

IEL Program

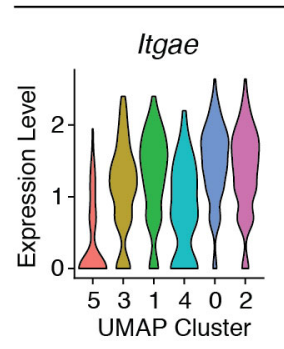

Nkg7
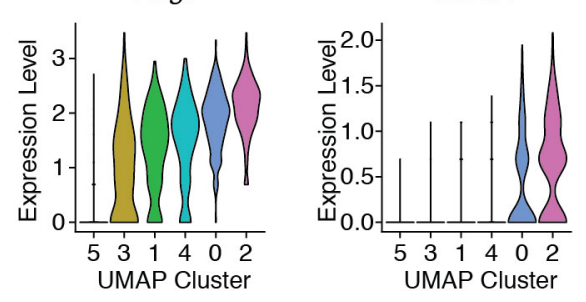

Gzma

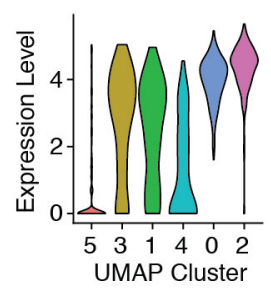

Col5

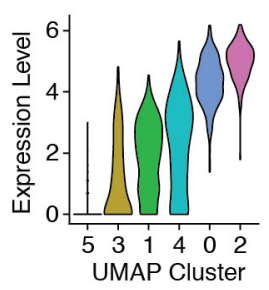

C

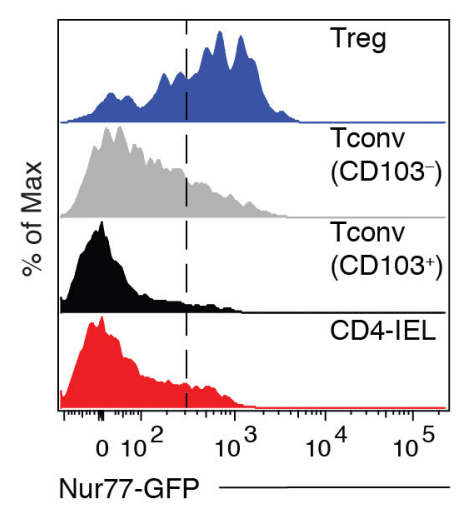


bioRxiv preprint do: https://doi.org/10.1101/2020.06.04.134510; this version posted June 5, 2020. The copyright holder for this preprint (which was not certified by peer review) is the author/funder. All rights reserved. No reuse allowed without permission.

A

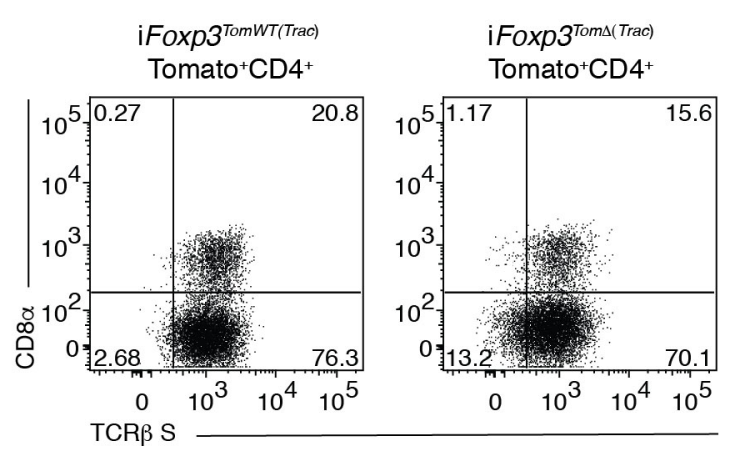

B

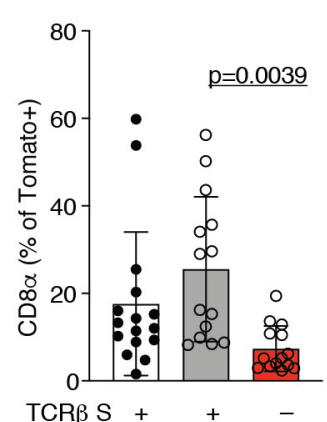

Figure 4

- iFoxp3 $3^{\text {TomWT(Trac) }}$

- iFoxp3 $3^{\text {Toms }(\text { Trace })}$

E

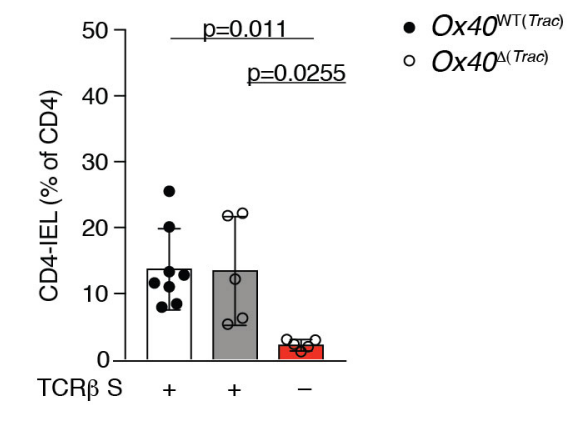

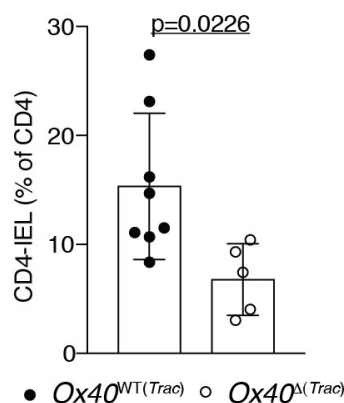
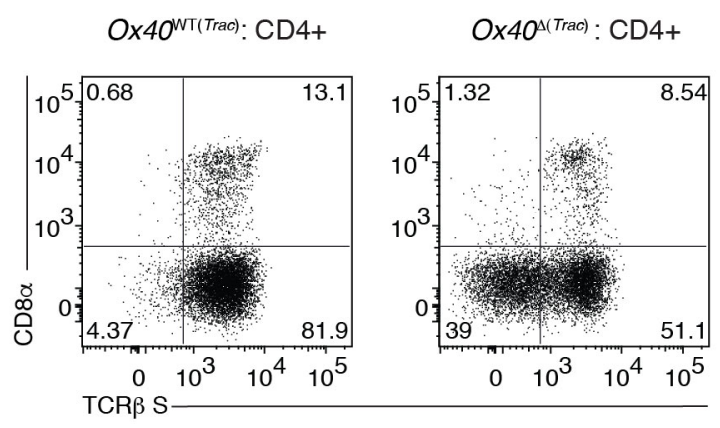

D 

bioRxiv preprint doi: https://doi.org/10.1101/2020.06.04.134510; this version posted June 5, 2020. The copyright holder for this preprint (whipligure 5
was not certified by peer review) is the author/funder. All rights reserved. No reuse allowed without permission.

A Tamoxifen at 5-7 wko; Analysis at $10-12.5 w k o$
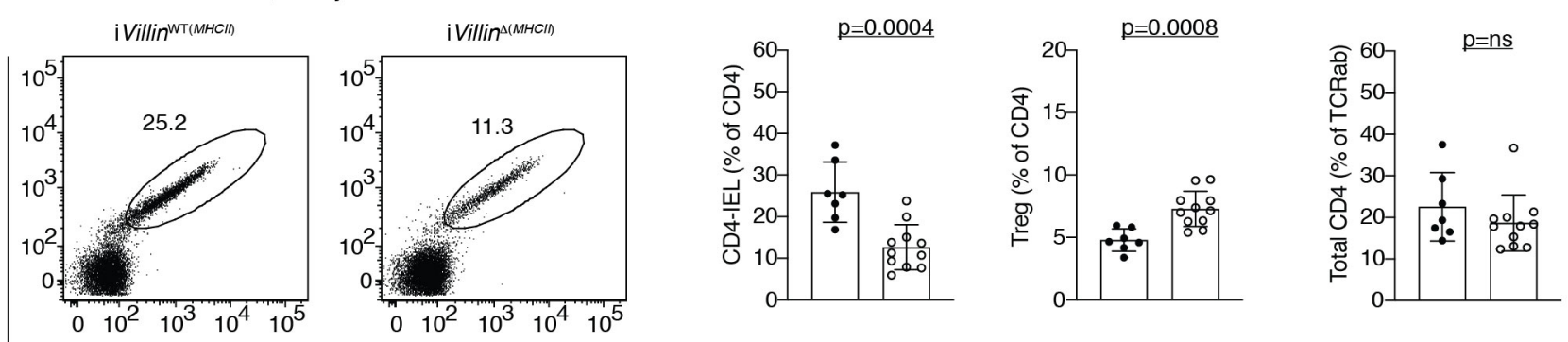

- iVillin ${ }^{\mathrm{WT}(M H C I)}$

○ iVillin ${ }^{\Delta(M H C I)}$

B

Tamoxifen at 10.5-12 wko; Analysis at 13-17wko
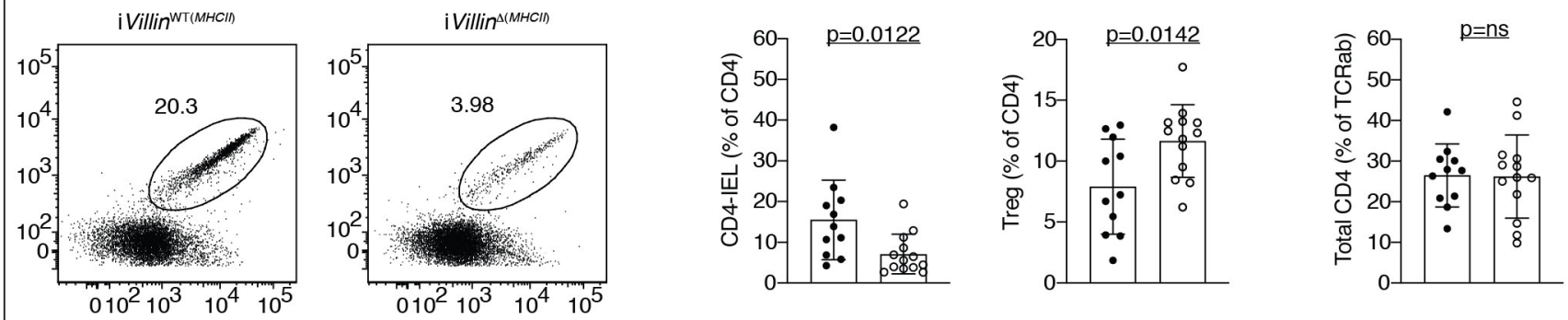

- iVillin ${ }^{\mathrm{WT}(M H C I I)}$

○ iVillin ${ }^{\Delta(M H C I)}$

C

Tamoxifen at 16 wko; Analysis at 21-22wko
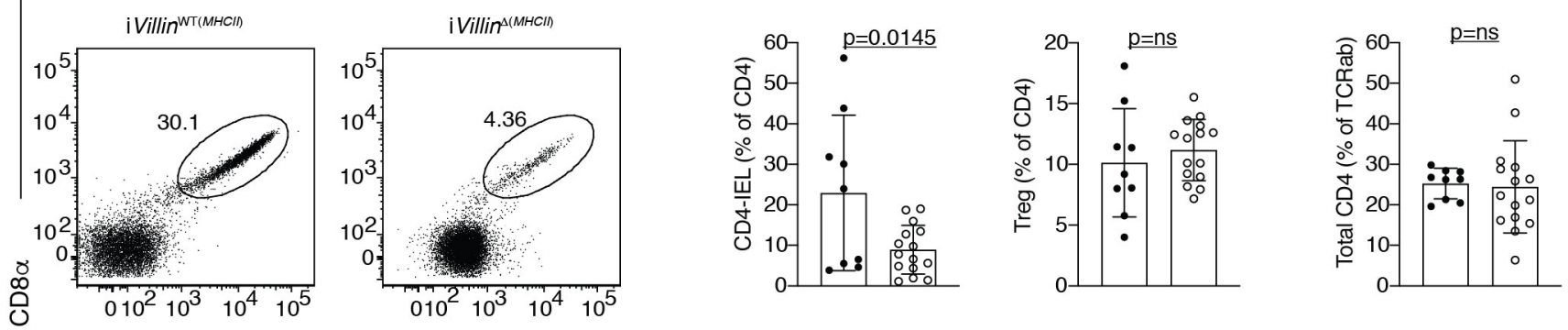

- iVillin $^{\mathrm{WT}(M H C I)}$

○ iVillin $\Delta(M H C l)$

TL-Tetramer 

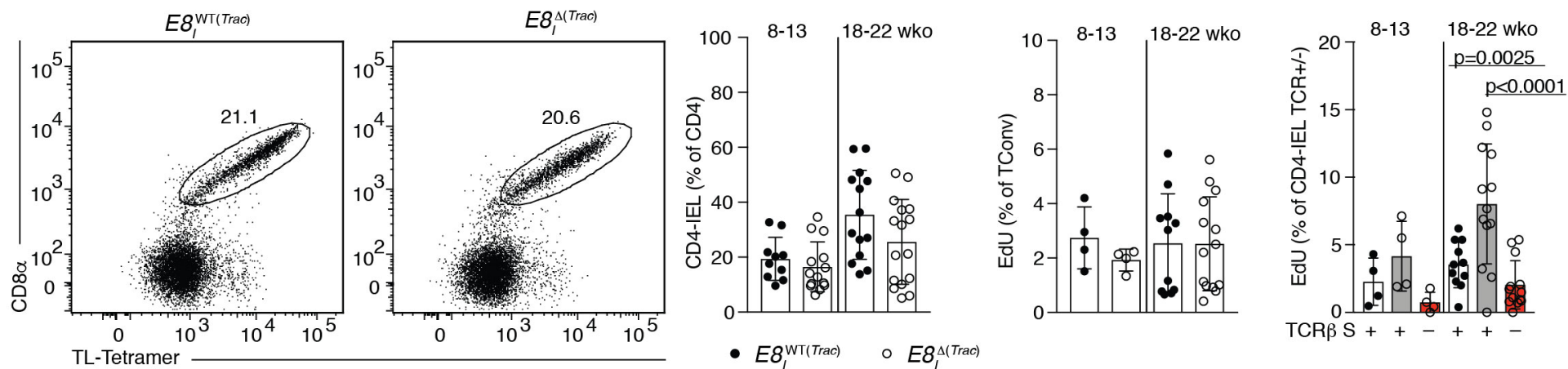

E

$\mathbf{F}$

G

CD4-IEL

- $E 8_{1}^{\mathrm{WT}(\text { Trac })} \quad \circ 8_{1}^{\Delta(\text { Trac })}$
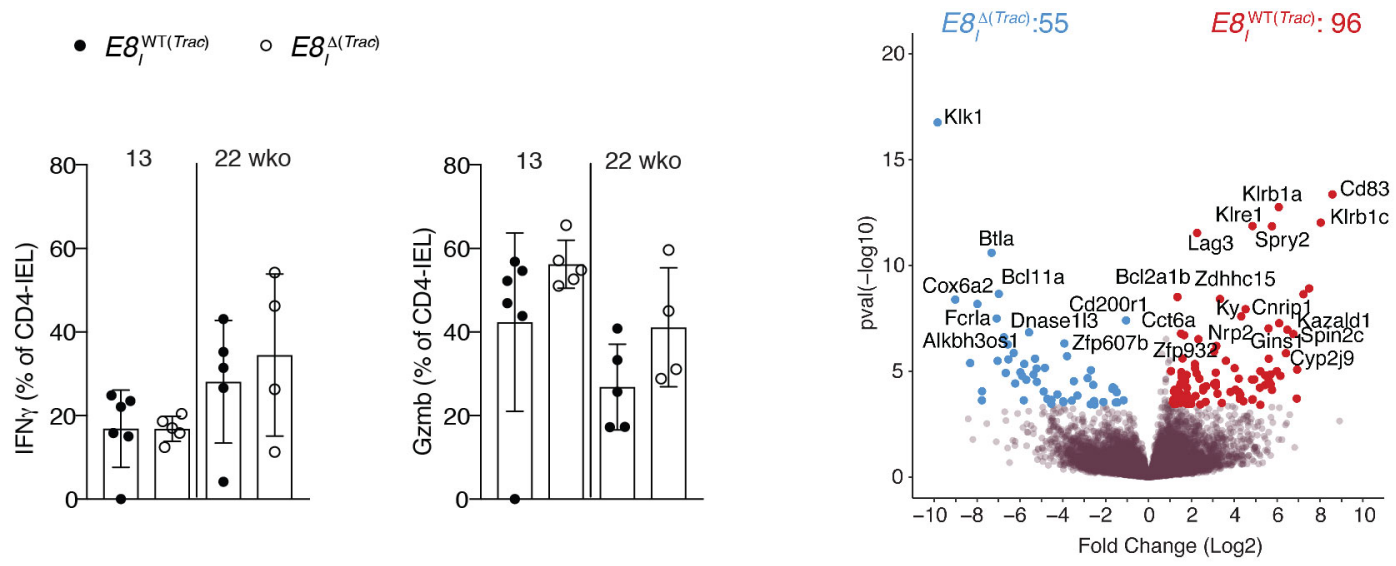

H

Enrichment $E 8_{1}^{\text {WT(Trac) }} \quad E 8_{l}^{\Delta(\text { Trac })}$

CD4-IEL: GO Pathways

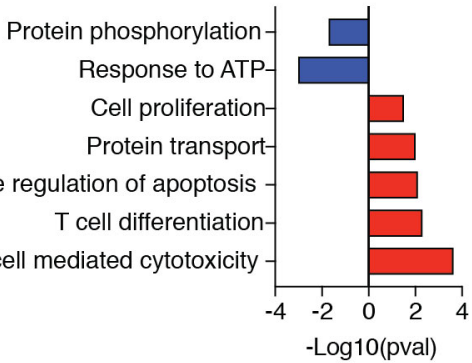

J

CD4-IEL Program: GSEA

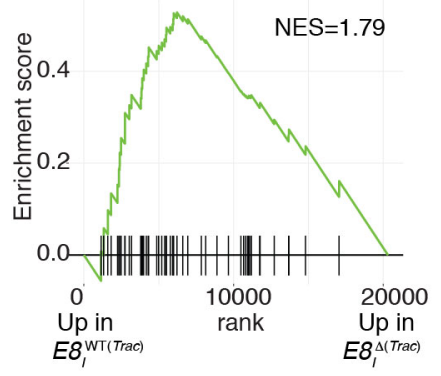

K

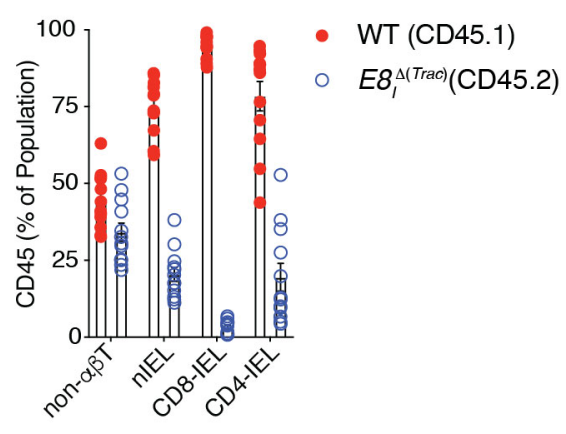

n-IEL
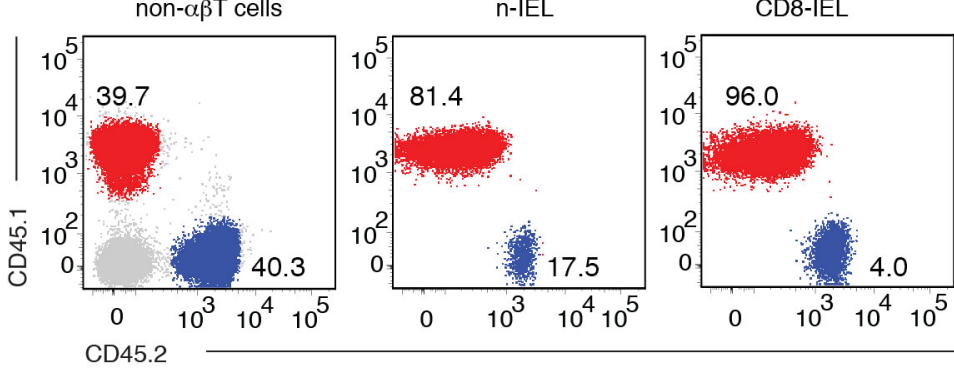

CD8-IEL
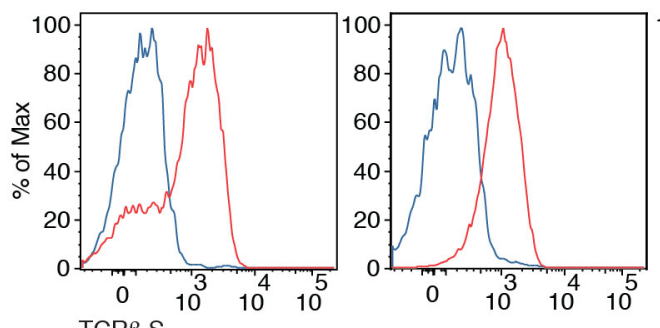

CD4-IEL

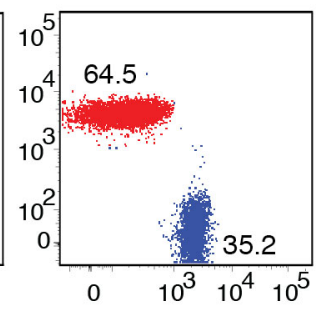

CD4-IEL

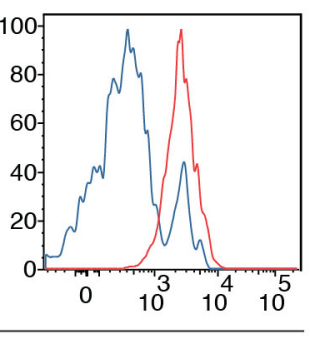


bioRxiv preprint doi: https://doi.org/10.1101/2020.06.04 134510; this version posted June 5, 2020. The copyright holder for this preprint (which

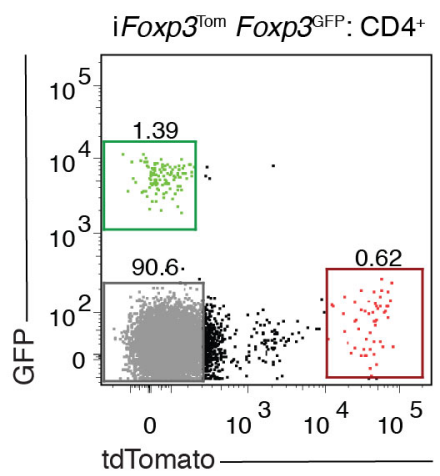
All rights reserved. No reuse allowed without permission.

Figure S1

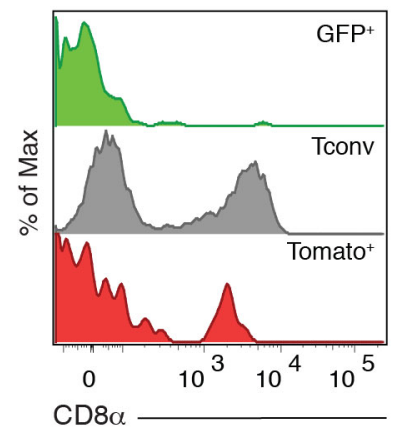

Mouse 2 (IE): CASSPPGQSNERLFF

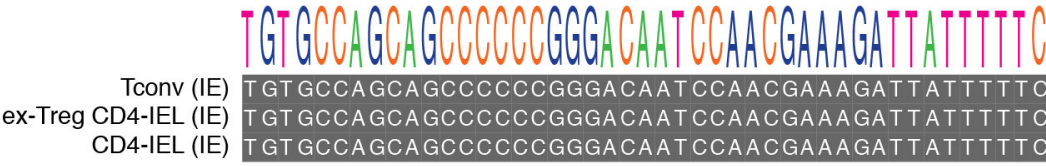

Mouse 2 (IE): CASLVGGDTEVFF

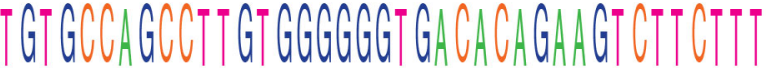

ex-Treg CD4-IEL (IE) T GT GCCA GCC T T GT GGGGGGT GA CA CA GAAGT C T T C T T T

CD4-IEL (IE) T GT GCCA GCC T T GT GGGGGGT GACA CA GAA GT C T T C T T T

C

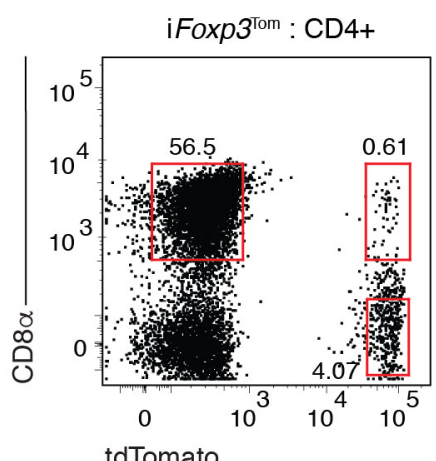

D
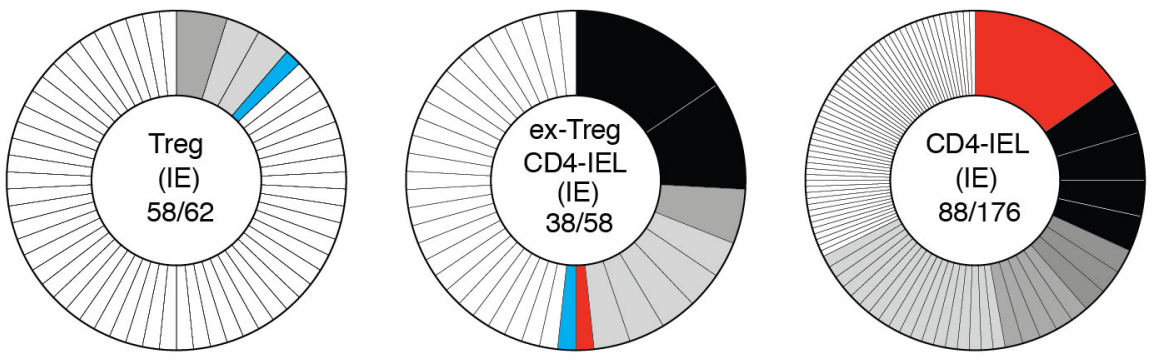

Sharing within mouse

Unique clones

$2 X$

$3 \times$

$4 X$

$5 x$

$>5 \times$ 

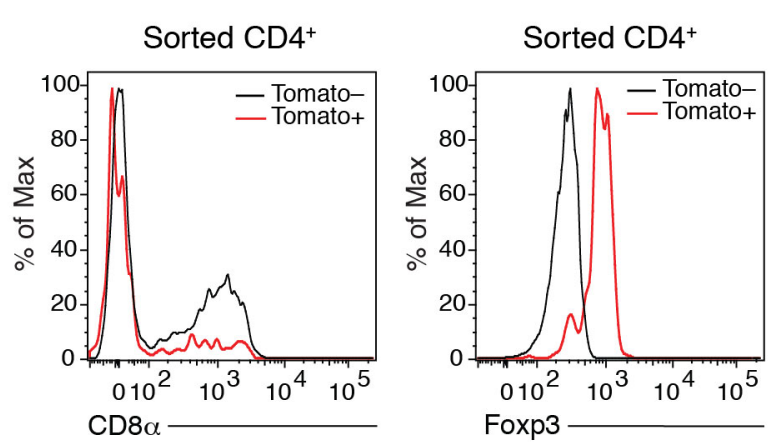

Genes

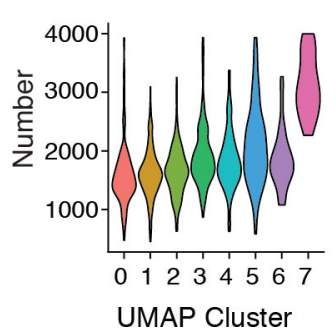

RNA molecules

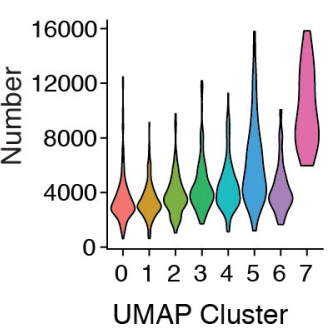

mtDNA

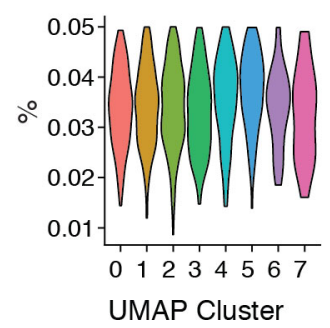

C
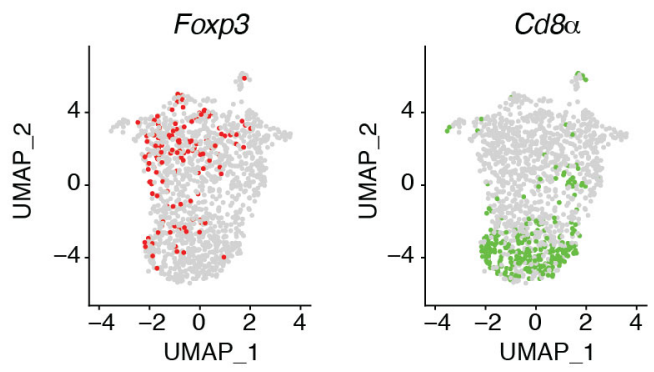

E

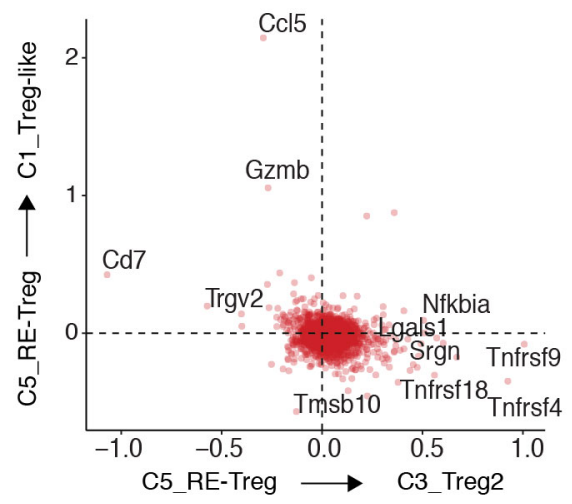

G

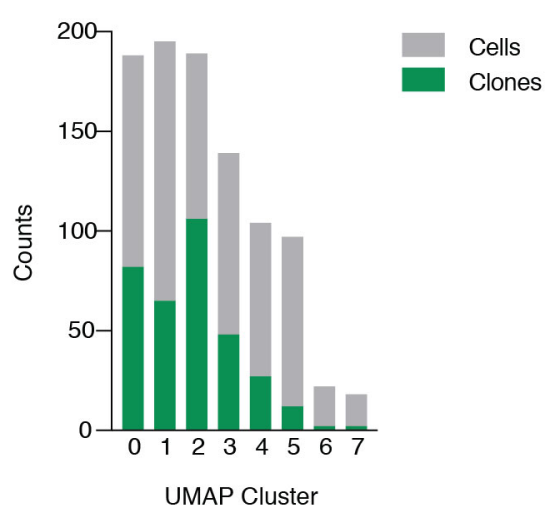

$\mathbf{F}$

H
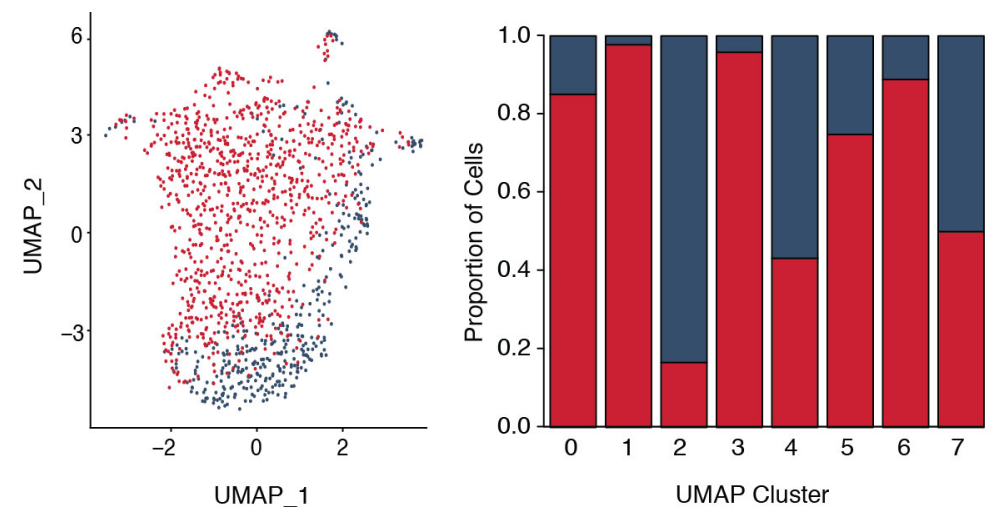

- Tomato $^{+}$- Tomato

Tomato negative: paired TCR $\alpha \beta$ CDR3

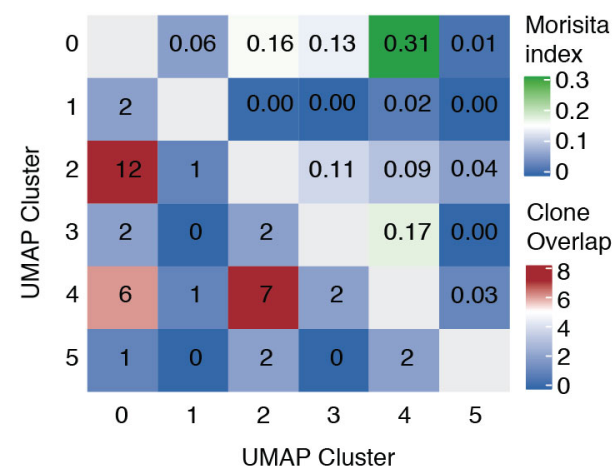

UMAP Clusters

0_Pre-IEL1

1_Treg-like

2_CD4-IEL

3_Treg

4_Pre-IEL2

5_RE-Treg

6_Treg

7_Cycling 
bioRxiv preprint doi: https://doi.org/10.1101/2020.06.04.134510; this version posted June 5, 2020. The copyright holder for this preprint (which was not certified by peer review) is the author/funder. All rights reserved. No reuse allowed without permission.

A

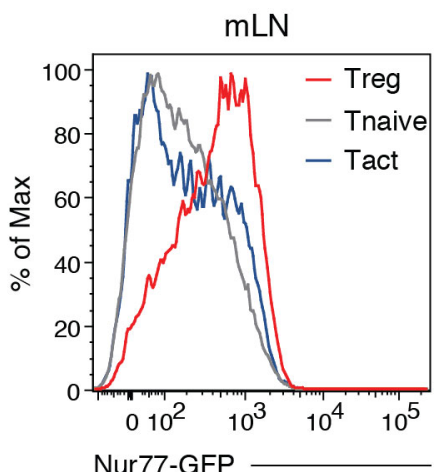

B

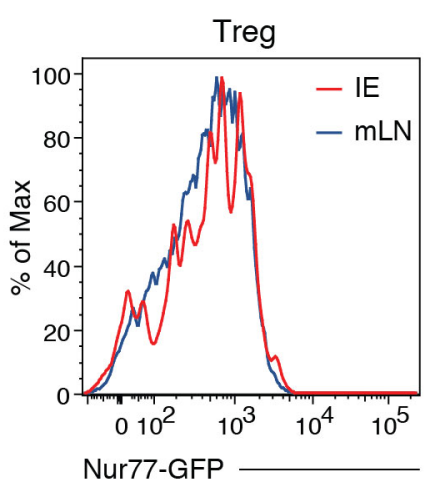

C

Figure S3

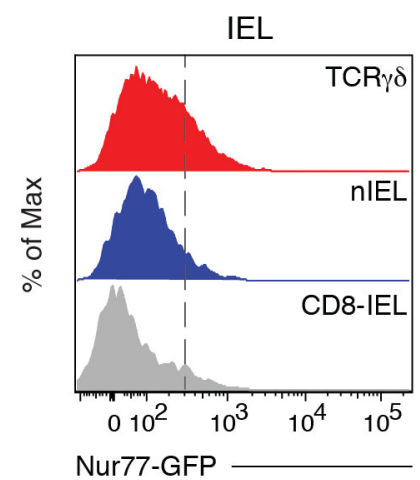


A bioRxiv preprint doi: https://doi.org/10.1101/2020.06.04.1345 B; this version posted June 5, 2020. The copyright holder for this preprinFigioure S4 was not certified by peer review) is the author/funder. All rights reserved. No reuse allowed without permission.

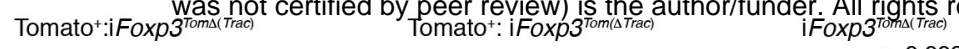
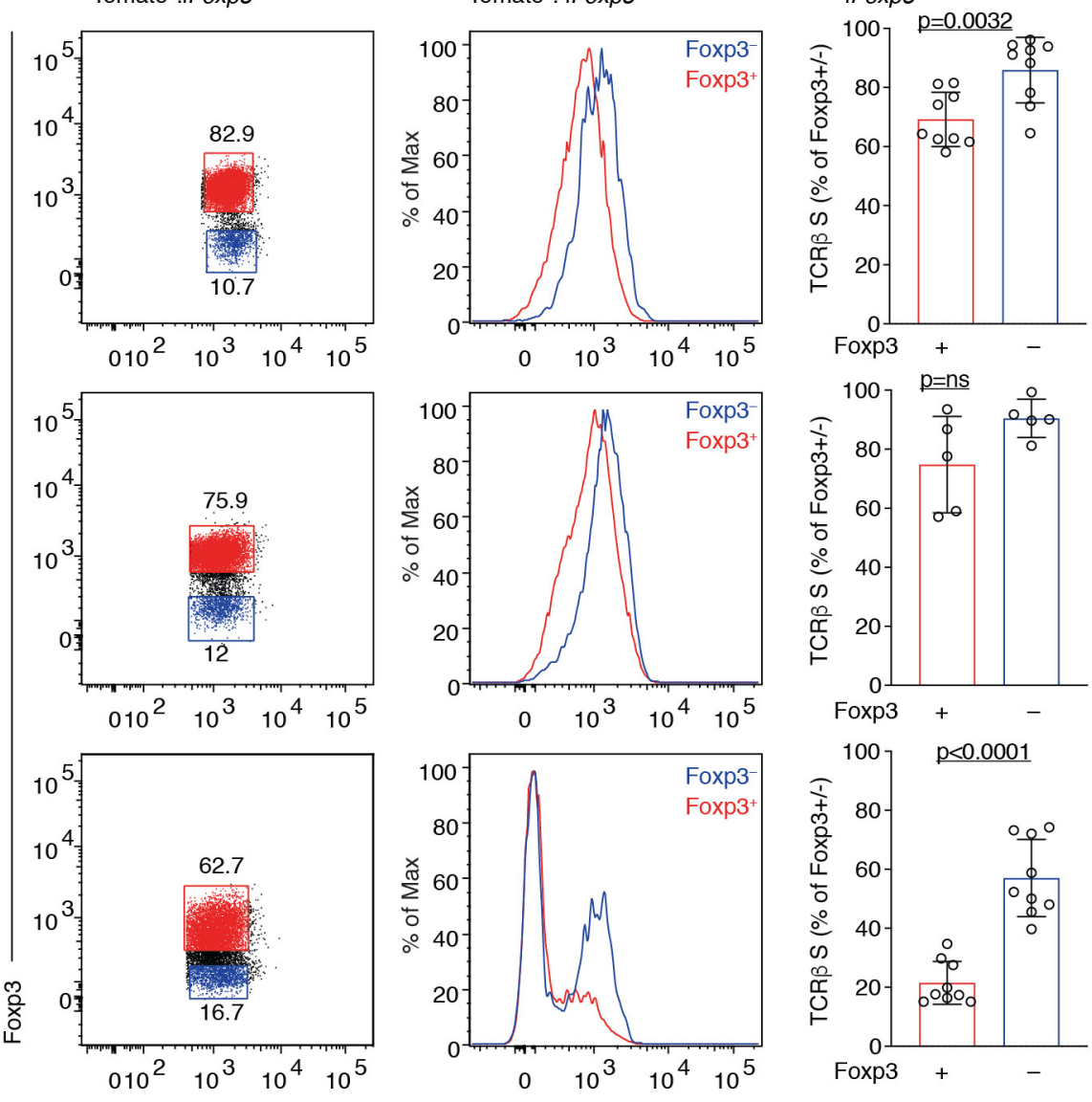

C
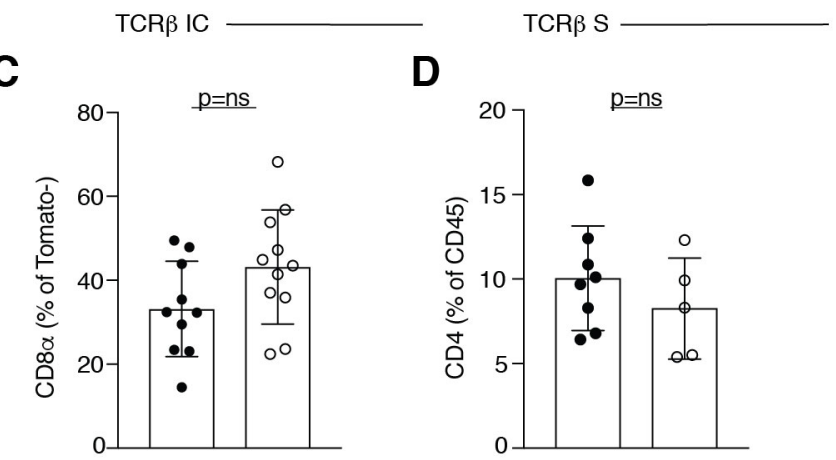

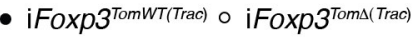

$\mathbf{F}$

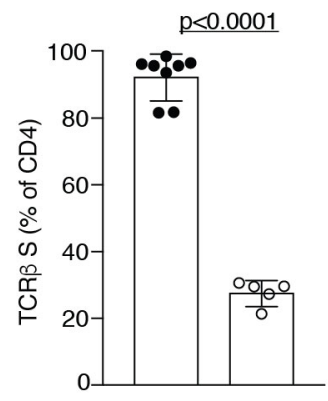

I

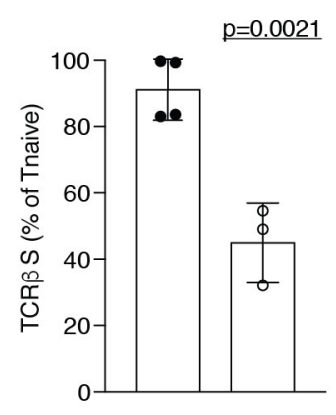

- $0 \times 40^{\text {WT(Trac) }} \circ O \times 4 O^{\text {(Trac) }}$
G

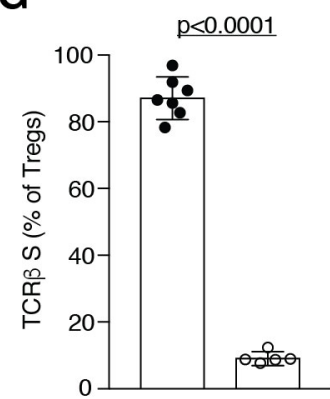

IE
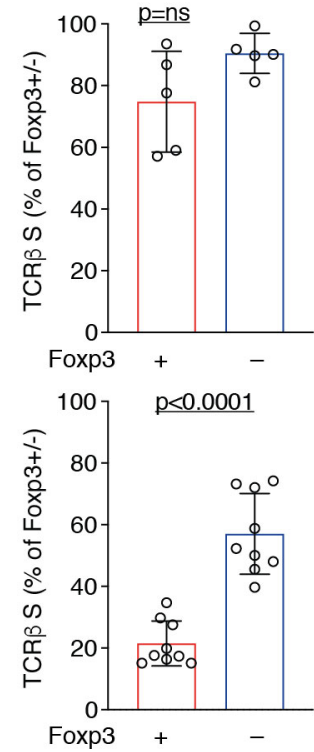

LP

E

mLN

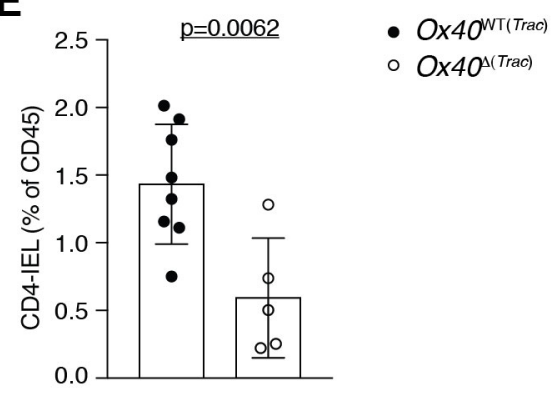

H

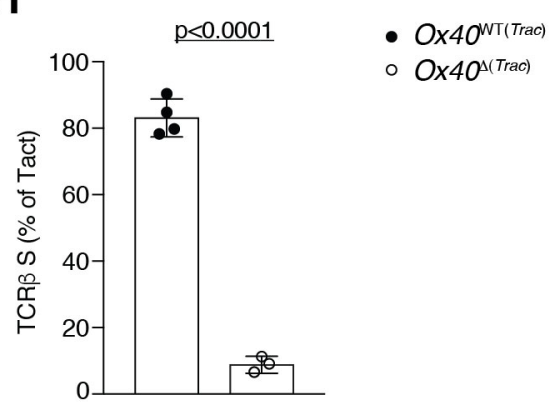

$\mathbf{J}$

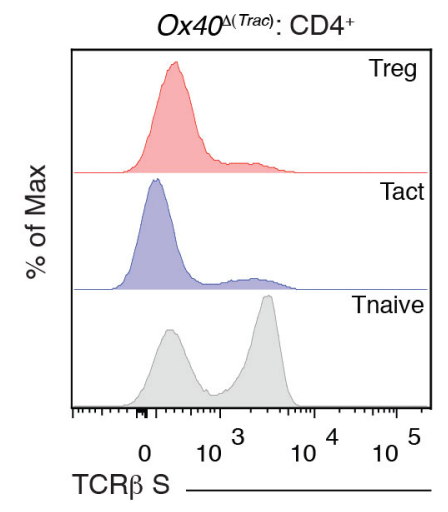


bioRxiv preprint doi: https://doi.org/10.1101/2020.06.04.134510; this version posted June 5, 2020. The copyright holder for this preprint (which was not certified by peer review) is the author/funder. All rights reserved. No reuse allowed without permission.

Figure S5

A

Tamoxifen at 10.5-12 wko; Analysis at 13-17wko Tamoxifen at 16 wko; Analysis at 21-22wko
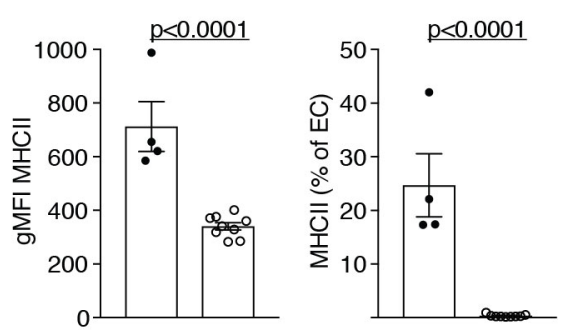

B
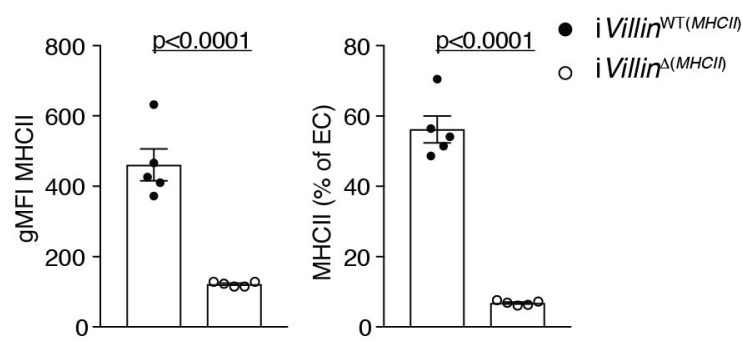

C

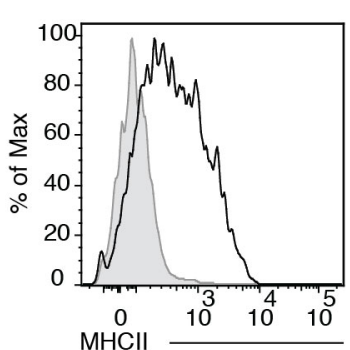

iVillin ${ }^{\mathrm{WT}(M H C I I)}$

iVillin ${ }^{\Delta(M H C I I)}$ 
bioRxiv preprint doi: https://doi.org/10.1101/2020.06.04.134510; this version posted June 5, 2020. The copyright holder for this preprint (which

A was not Brtified by peer review) is the athor/funder. All rights reserved. Do reuse allowed without permission $\mathbf{E}$

Figure S6

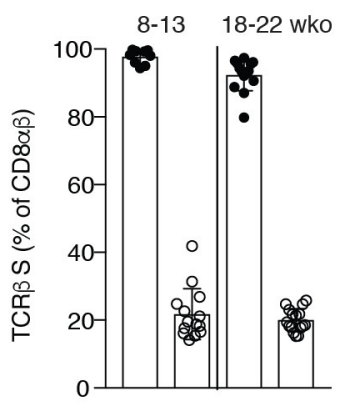

$\mathbf{F}$

- $E 8_{1}^{\mathrm{WT}(\text { Trac })}$ o $E 8_{1}^{\Delta(\text { Trac })}$

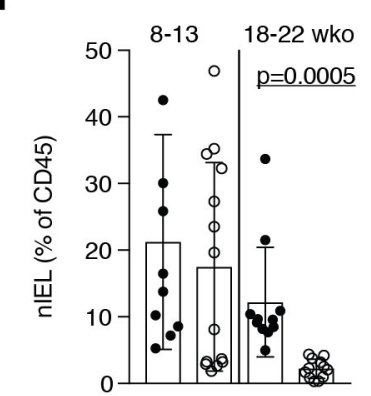

- $E 8_{1}^{W T(T r a c)} \circ E 8_{I}^{\Delta(T r a c)}$

K

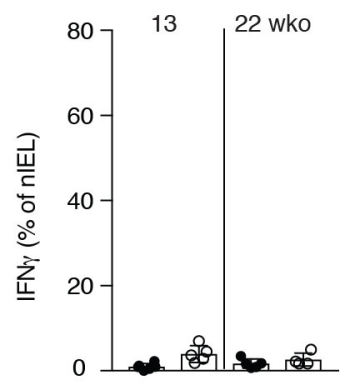

- $E 8_{I}^{\mathrm{WT}(T \mathrm{Trac})} \circ 8_{I}^{\Delta(\mathrm{Trac})}$

$\mathbf{N}$
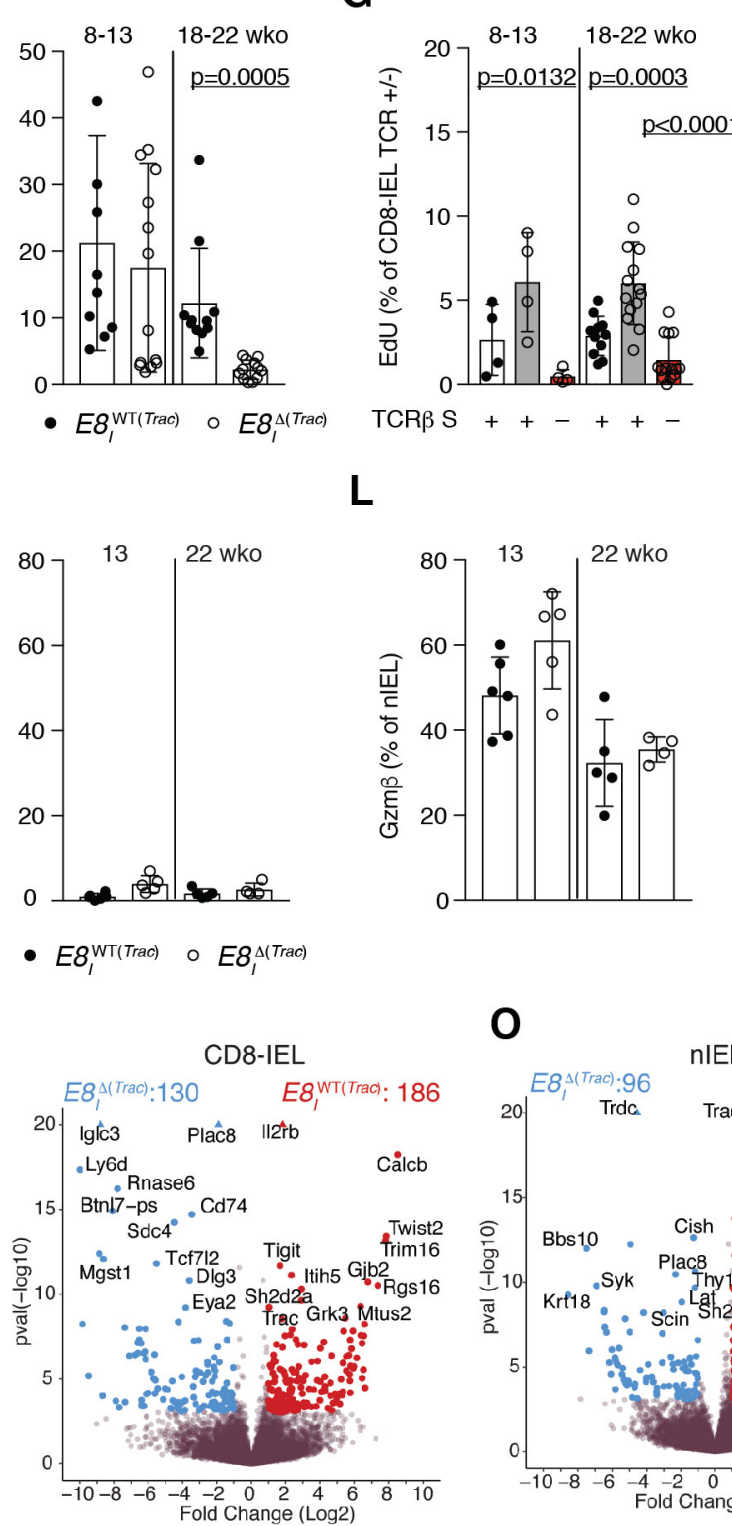

L

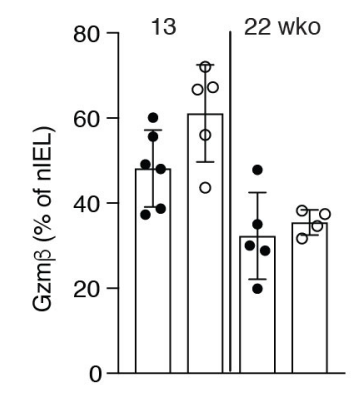

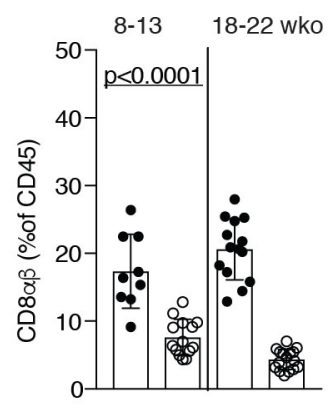

H

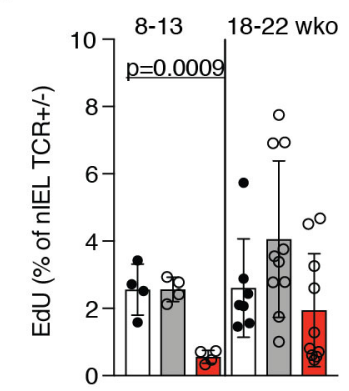

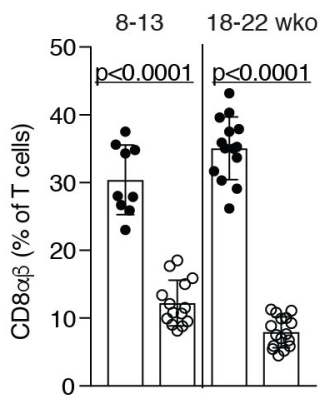

I

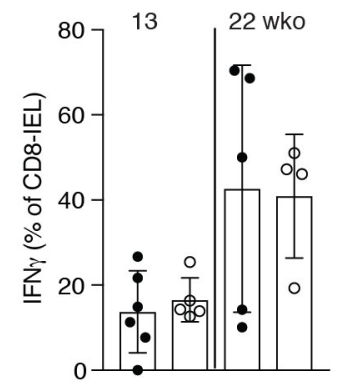

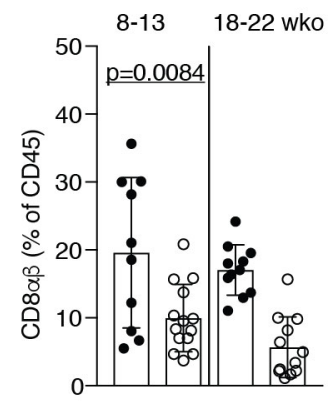

$\mathbf{J}$

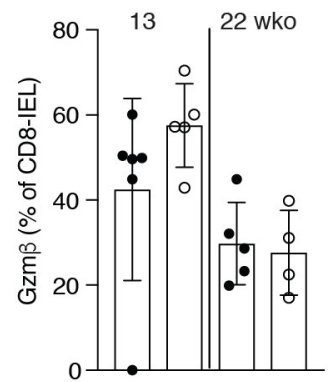

M

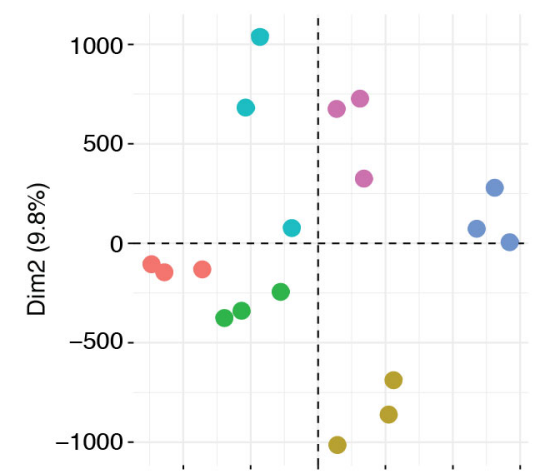

-2000-1000 $0 \quad 100020003000$

Dim1 $(80.1 \%)$
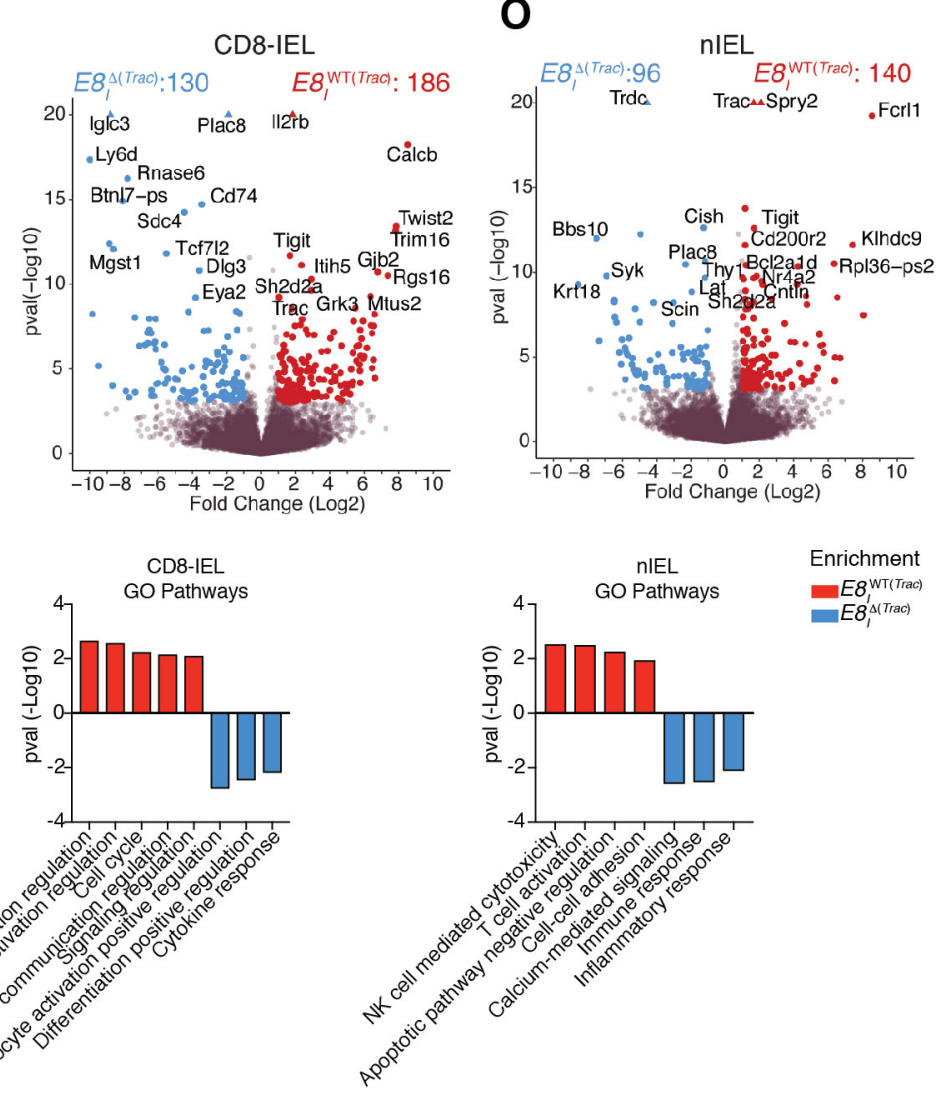